\title{
Time-aware PageRank for bibliographic networks
}

\section{Dalibor Fiala}

University of West Bohemia, Univerzitní 8, 30614 Plzeň, Czech Republic

Phone: +420 3776324 29, fax: +420 3776324 01, email: dalfia@kiv.zcu.cz

\begin{abstract}
In the past, recursive algorithms, such as PageRank originally conceived for the Web, have been successfully used to rank nodes in the citation networks of papers, authors, or journals. They have proved to determine prestige and not popularity, unlike citation counts. However, bibliographic networks, in contrast to the Web, have some specific features that enable the assigning of different weights to citations, thus adding more information to the process of finding prominence. For example, a citation between two authors may be weighed according to whether and when those two authors collaborated with each other, which is information that can be found in the co-authorship network. In this study, we define a couple of PageRank modifications that weigh citations between authors differently based on the information from the co-authorship graph. In addition, we put emphasis on the time of publications and citations. We test our algorithms on the Web of Science data of computer science journal articles and determine the most prominent computer scientists in the 10-year period of 1996 - 2005. Besides a correlation analysis, we also compare our rankings to the lists of ACM A. M. Turing Award and ACM SIGMOD E. F. Codd Innovations Award winners and find the new time-aware methods to outperform standard PageRank and its timeunaware weighted variants.
\end{abstract}

Keywords: PageRank, citations, collaboration, time, salient researchers, computer science.

\section{Introduction}

When Brin and Page made public their PageRank algorithm in 1998 (Brin and Page, 1998), they would probably hardly have imagined what an enormous impact on computer science this would have in the decade to come. They presented a straightforward method of computing the importance of Web pages using the link structure of the (then still relatively new) World Wide Web. The same concept of "authoritativeness" of Web pages was, at approximately the same time, invented independently by Kleinberg (1999). The idea was surprisingly simple: if a link from one Web page to another one can be viewed as a vote then popular pages will have many in-links. In addition, if those in-links come from pages that themselves have many in-links, popularity becomes prestige. It was soon discovered that this This is a preprint of the JOI submission. 
recursive technique (applied successfully by Google) could be used to evaluate (rank) nodes in any (directed) graph. Bibliographic citation networks of papers, authors, journals, institutions, or even countries are good examples of such graphs and some studies making use of PageRank or related methods to find prominent players in them are touched upon in Section 2. However, researchers also felt the need to weigh the edges in bibliographic citation networks (unlike the original PageRank which was unweighted) based on the differences between the Web graph and the citation networks. First, bibliographic networks often contain information that can add value to citations, e.g. citation counts or co-authorship information. Second, unlike the Web graph, bibliometric networks include time, e.g. publication (citation) years, which could also help weigh citations more discriminately. And third, bibliometric networks are static in that citations always point from newer to older publications and they can never be removed. Fiala et al. (2008) addressed the first problem. They assigned more or less weight to the edges in a citation graph of authors based on the information from a coauthorship graph. The principal assumption was that a citation from a colleague should contribute less to the prestige of the cited author than a citation from a "foreign" researcher. On the other hand, this penalization could be mitigated in some circumstances, for instance, if the number of common publications of those two authors is relatively small compared to the total number of publications by the authors. Time in terms of publication (and thus citation or collaboration) years was ignored in this scenario. However, it is clear that if a citation is made before any common papers are published, it should not be considered a "friendly" citation from a colleague. This problem is addressed in this article. As for the third issue (static citations), some proposals to solve this problem are mentioned in the section on related work.

The principal objectives of the research reported in this paper are as follows:

- Define "time-aware" modifications of the "bibliographic PageRank" formula based on the work by Fiala et al. (2008) that take into account the time (year) when articles are published and citations are made.

- Apply the time-aware as well as the original (time-unaware) bibliographic PageRank variants to a large citation network of computer science researchers to find out the most prominent computer scientists.

- Compare the rankings of researchers generated by the new methods with each other as well as with other established bibliometric techniques in terms of a correlation analysis and a confrontation with the lists of ACM A. M. Turing Award (Turing Award) and ACM SIGMOD E. F. Codd Innovations Award (Codd Award) winners.

This is a preprint of the JOI submission. 
This article is organized in the following way: after introducing PageRank and our research goals in Section 1, related work on measuring computer science and various modifications of PageRank is reviewed in Section 2. Afterwards, in Section 3, we describe in detail an extension to the standard PageRank that is suitable for bibliographic networks and that can exploit the time information present in them. Section 4 is concerned with the data to which we applied the novel methods and then we discuss the experimental results in Section 5. Finally, we draw the main conclusions and outline our future work in Section 6.

\section{Related work}

This section on related work consists of three main paragraphs. The first one is concerned with previous bibliometric work on computer science, which has, somewhat surprisingly, been relatively little explored in the past. The second paragraph enumerates the principal studies known to the author that have sought to add weights to the basic PageRank formula and, finally, research into time-based weighting of PageRank is presented in the third paragraph.

\subsection{Computer science}

Bar-Ilan (2010) studied how publication and citation counts of some highly cited computer science researchers changed after conference proceedings papers had been added to the Web of Science (WoS). Franceschet (2010) investigates prestige, popularity, and productivity of computer science researchers with regard to journal versus conference papers. He defines a prestigious computer scientist as an ACM A. M. Turing Award winner. Wainer et al. (2011) studied how many publications by computer science researchers are not indexed by established bibliographic databases compared to other scientific fields and concluded that, on average, $66 \%$ of a computer scientist's work is unknown to the Web of Science. Bibliometric studies on computer science based on the data from the CiteSeer digital library are presented by Fiala (2011, in press).

\subsection{PageRank and weighted PageRank}

Bollen et al. (2006) assigned weights based on the number of citations to the edges in the citation network of journals and computed weighted PageRanks for the journals. Chen et al. (2007) calculate PageRank of papers from a set of physics journals. Different weighting and normalization schemes were applied to PageRank by Bergstrom (2007) and González-Pereira et al. (2010) to compute journal prestige. The corresponding scores are called Eigenfactor (or 
Article Influence when related to papers) and SCImago Journal Rank (SJR), respectively. Ding (2011) computes weighted PageRank for authors in the information retrieval field. She assigns weights based on the number of publications or citations to nodes rather than edges, and experiments with various damping factors in the PageRank formula. A similar study for author co-citation networks is conducted by Ding et al. (2009). Yan and Ding (2011) explore co-authorship networks in the informetrics field. They calculate PageRank for authors with different damping factors and draw the conclusion that the damping factor does not have much influence on ranking in this type of network. They also define a weighted PageRank in which more weight is assigned to authors with more citations. Ma et al. (2008) computed PageRank for papers in the field of biochemistry and molecular biology. Xing and Ghorbani (2004) defined the "weighted PageRank" by multiplying the rank of each in-linking node by two factors: the in-degree of the current node divided by the sum of in-degrees of the nodes linked to by the in-linking node, and the out-degree of the current node divided by the sum of out-degrees of the nodes linked to by the in-linking node. This enabled more rank to be transferred to more "popular" nodes, i.e. to those that had relatively numerous in-links and/or out-links. The authors reported some success compared to the standard PageRank in obtaining more relevant results from a (very) small set of Web pages. Their approach does not seem reasonable in the case of citation networks of papers or authors because it is not clear why a paper (author) should be rewarded for citing many other papers (authors), i.e. the out-degree factor is doubtful. If just the in-degree factor was retained, their method would somewhat resemble the work by Ding (2011). Sidiropoulos and Manolopoulos (2005) adapted PageRank for publication citation networks in that they gave less weight to the citations from more distant publications (in terms of graph path). They were also the first to compare new ranking methods with established awards such as the ACM SIGMOD E. F. Codd Innovations Award.

\subsection{Weighted PageRank considering time}

Walker et al. (2007) ranked publications in two distinct citation networks of physics papers. They included the age of publications in the PageRank algorithm by favouring citations from more recent articles. They also experimentally verified the until then theoretical concept that the average path length of a random surfer following citations between research publications is only around two. Yan and Ding (2010) also bring time into play when they give more weight to more recent citations (i.e. to the citations from publications that appear shortly after the cited papers). In addition, they more heavily weight citations from prestigious articles, but their prestige (article influence score) is not computed recursively in a self-contained way This is a preprint of the JOI submission. 
(like PageRank) but rather taken from a citation database. In their "TimedPageRank", Yu et al. (2004) simply decrease the weight of a citation exponentially with the citation age using a base (decay rate) of 0.5 . For the prediction of popularity a paper will enjoy in future years, they apply an "ageing factor" as well that linearly declines a paper's TimedPageRank with the paper's age.

In summary, all the authors of the above studies on (time-)weighted PageRank report its superiority to the standard PageRank but, at the same time, find a high correlation of various PageRank variants and other bibliometric measures such as citation counts. None of the studies, however, has combined time information from both the citation and collaboration graphs to rank computer science researchers via the "time-aware" PageRank described in this paper.

\section{Methods}

The methods of time-aware PageRank described in this paper are based on the techniques used by Fiala et al. (2008) by including the time factor in their PageRank modifications that take into account not only citations between authors but also other information such as the number of common publications between two authors linked by a citation. The key concept was that citations between authors should not be weighted the same but should rather be based on a number of factors reflecting the behaviour of authors. For instance, a citation between two authors who often collaborate with each other is considered less valuable than that between two authors who have never co-authored a single publication. We invite the reader to get more explanations and see examples in Fiala et al. (2008). In the following paragraphs, we will re-define "the bibliographic PageRank" from our previous work and expand it with time aspects so that it allows for the computation of "time-aware bibliographic PageRank".

\subsection{Definitions}

To understand Figure 1, let $G^{P}=\left(P \cup A, E^{P}, \boldsymbol{T}^{P}\right)$ be an undirected, edge-weighted, bipartite graph (co-authorship graph), $P \cup A$ a set of vertices $\left(P=\left\{p_{1}, \ldots, p_{n}\right\}\right.$ a set of publications, $A=\left\{a_{1}, \ldots, a_{m}\right\}$ a set of authors), $E^{P} \subseteq P \times A$ a set of edges, and $\boldsymbol{T}^{P}$ an $n \times m$ matrix of nonnegative weights - publication years. Each edge $\{p, a\} \in E^{P}, p \in P, a \in A$ means that author $a$ has (co-)authored publication $p$ that appeared in year $\boldsymbol{T}_{p a}^{P}$. (If $\boldsymbol{T}^{P}{ }_{i j}=0$ then there is no such edge $\{i, j\}$ in $\mathrm{E}^{\mathrm{P}}$.) Let $G^{C}=\left(P, E^{C}, \boldsymbol{T}^{C}\right)$ be a directed edge-weighted graph (publication citation graph), $P=\left\{p_{1}, \ldots, p_{n}\right\}$ a set of vertices (the same set of publications), $E^{C} \subseteq P \times P$ a

This is a preprint of the JOI submission. 
set of edges (citations between publications), and $\boldsymbol{T}^{C}$ an $n \times n$ matrix of non-negative weights - citation years. Each edge $\left\{p_{1}, p_{2}\right\} \in E^{C}, p_{1} \in P, p_{2} \in P$ means that publication $p_{1}$ from year $\boldsymbol{T}_{p 1 p 2}^{C}$ cites publication $p_{2}$. (If $\boldsymbol{T}^{C}{ }_{i j}=0$ then there is no such edge $\{i, j\}$ in $\mathrm{E}^{\mathrm{C}}$.) Now, we will combine the two graphs $G^{P}$ and $G^{C}$ into one more graph we will further work with. Let $G=(A, E)$ be a directed edge-weighted graph (author citation graph), $A=\left\{a_{1}, \ldots, a_{m}\right\}$ a set of vertices (the same set of authors) and $E \subseteq A \times A$ a set of edges (citations between authors). For every $p \in P$ let $A_{p}=\left\{a \in A: \exists\{p, a\} \in E^{P}\right\}$ be the set of authors of publication $p$. For each $\left(a_{1}, a_{2}\right), a_{1} \in A, a_{2} \in A, a_{1} \neq a_{2}$ where there exists $\left(p_{1}, p_{2}\right) \in E^{C}$ such that $\left\{p_{1}, a_{1}\right\} \in E^{P}$ and $\left\{p_{2}, a_{2}\right\} \in E^{P}$ and $A_{p 1} \cap A_{p 2}=\varnothing$ (i.e. no common authors in citing and cited publications are allowed) there is an edge $\left(a_{1}, a_{2}\right) \in E$ (no parallel edges are admitted). Thus, $\left(a_{1}, a_{2}\right) \in E$ if and only if $\exists\left(p_{1}, p_{2}\right) \in E^{C} \wedge \exists\left\{p_{1}, a_{1}\right\} \in E^{P} \wedge \exists\left\{p_{2}, a_{2}\right\} \in E^{P} \wedge A_{p 1} \cap A_{p 2}=\varnothing \wedge a_{1} \neq a_{2}$.

Fig. 1 should be placed here.

Before assigning weights to the edges in $E$, we further define:

- $w_{u, v}=|C|$ where $C=\left\{p_{1} \in P: \exists\left\{p_{1}, u\right\} \in E^{P} \wedge \exists\left\{p_{2}, v\right\} \in E^{P} \wedge \exists\left\{p_{1}, p_{2}\right\} \in E^{C} \wedge p_{1} \neq p_{2}\right\}$, as the number of citations from $u$ to $v$;

- $f_{u, v}^{t}=\left|P_{u}^{t}\right|+\left|P_{v}^{t}\right|$ where $P_{i}^{t}=\left\{p \in P: \exists\{p, i\} \in E^{P} \wedge \boldsymbol{T}_{p i}^{P}<t\right\}$, as the number of publications by $u$ appearing before year $t$ plus the number of publications by $v$ appearing before year $t$ (called publicationsT); if $t=\infty$ (i.e. time is not taken into account), $f_{u, v}^{t}$ becomes $f_{u, v}$ (time-unaware, called publications);

- $\quad c_{u, v}^{t}=\left|C P^{t}\right|$ where $C P^{t}=\left\{p \in P: \exists\{p, u\} \in E^{P} \wedge \exists\{p, v\} \in E^{P} \wedge \boldsymbol{T}_{p u}^{P}<t \wedge \boldsymbol{T}_{p v}^{P}<t\right\}$, as the number of common publications by $u$ and $v$ published before year $t$ (called collaborationT); if $t=\infty, c_{u, v}^{t}$ becomes $c_{u, v}$ (called collaboration);

- $h d_{u, v}^{t}=\left|A D C_{u}^{t}\right|+\left|A D C_{v}^{t}\right|$ where $A D C_{i}^{t}=\left\{\mathrm{a} \in A: \exists \mathrm{p} \in P\right.$ such that $\{p, a\} \in E^{P} \wedge\{p, i\} \in E^{P}$ $\left.\wedge \boldsymbol{T}_{p a}^{P}<t \wedge \boldsymbol{T}_{p i}^{P}<t\right\}$, as the number of all distinct co-authors of $u$ in the papers published before year $t$ plus the number of all distinct co-authors of $v$ in the papers published before year $t$ (called allDistCoauthorsT) ); if $t=\infty, h d_{u, v}^{t}$ becomes $h d_{u, v}$ (called allDistCoauthors);

- $h_{u, v}^{t}=\left|A D C_{u}^{t}\right|+\left|A D C_{v}^{t}\right|$ where $A D C_{i}^{t}$ is defined as above, but is a multiset, as the number of all co-authors of $u$ in the papers published before year $t$ plus the number of all co-authors of $v$ in the papers published before year $t$ (called allCoauthorsT); if $t=\infty, h_{u, v}^{t}$ becomes $h_{u, v}$ (called allCoauthors); 
- $t d_{\mathrm{u}, v}^{t}=\left|D C A^{t}\right|$ where $D C A^{t}=\left\{a \in A: \exists \mathrm{p} \in P\right.$ such that $\{p, a\} \in E^{P} \wedge\{p, u\} \in E^{P} \wedge$ $\left.\{p, v\} \in E^{P} \wedge \boldsymbol{T}_{p u}^{P}<t \wedge \boldsymbol{T}_{p v}^{P}<t\right\}$, as the number of distinct co-authors in the common publications by $u$ and $v$ appearing before year $t$ (called distCoauthorsT); if $t=\infty, t d_{u, v}^{t}$ becomes $t d_{u, v}$ (called distCoauthors);

- $t_{u, v}^{t}=\left|D C A^{t}\right|$ where $D C A^{t}$ is defined as above, but is a multiset, as the number of coauthors in the common publications by $u$ and $v$ appearing before year $t$ (called allDistCoauthorsT); if $t=\infty, t_{u, v}^{t}$ becomes $t_{u, v}$ (called allDistCoauthors);

- $g_{u, v}^{t}=f_{u, v}^{t}-\left|S P_{u}^{t}\right|-\left|S P_{v}^{t}\right|$ where $S P_{i}^{t}=\left\{p \in P:\{p, i\} \in E^{P} \wedge d_{G^{P}}(p)=1 \wedge \boldsymbol{T}_{p i}^{P}<t\right\}$, as the number of publications by $u$ that appeared before year $t$, where $u$ is not the only author, plus the number of publications by $v$ that appeared before year $t$, where $v$ is not the only author (called allCollaborations $T$ ); if $t=\infty, g_{u, v}^{t}$ becomes $g_{u, v}$ (called allCollaborations).

\subsection{Time-aware PageRank}

Now, we associate a vector of weight pairs $\boldsymbol{\tau}_{u v}=\left(\left(c_{u, v}^{t 1}, b_{u, v}^{t 1}\right)^{1},\left(c_{u, v}^{t 2}, b^{t 2}{ }_{u, v}\right)^{2}, \ldots,\left(c_{u, v}^{t k}\right.\right.$, $\left.b_{u, v}^{t k}\right)^{k}$ ) with each edge $(u, v) \in E$, where $k=w_{u, v}$ (the number of citations from author $u$ to author $v$ ) and $t 1 \ldots t k$ are the citation years selected as all those non-zero elements $\boldsymbol{T}_{i j}^{C}$, where $i \in P_{u}$ and $j \in P_{v}$, and we denote $P_{a}=\left\{p \in P: \exists\{p, a\} \in E^{P}\right\}$ as the set of publications of every author $a \in A . w_{u, v}$ and $c_{u, v}^{t}$ are described above, and $b_{u, v}^{t}$ can be equal to one of the seven following values according to the semantics of edge weights we want to stress: a) zero, b) $f_{u, v}^{t}$, c) $h_{u, v}^{t}$, d) $h d_{u, v}^{t}$, e) $g_{u, v}^{t}$, f) $t_{u, v}^{t}$, g) $t d_{u, v}^{t}$. We then define the rank $R(u)$ for author $u$ as follows, bearing in mind that the superscipt $i$ means an index in vector $\tau$ and not a year:

$$
\mathrm{R}(u)=\frac{1-d}{|A|}+d \sum_{(v, u) \in E} \mathrm{R}(v) \frac{\sum_{i=1}^{w_{v, u}} \frac{1}{\frac{c_{v, u}^{i}+1}{b_{v, u}^{i}+1} \sum_{(v, j) \in E} 1}}{\sum_{(v, k) \in E} \sum_{i=1}^{w_{v, k}} \frac{1}{\frac{c_{v, k}^{i}+1}{b_{v, k}^{i}+1} \sum_{(v, j) \in E} 1}} .
$$

If we wish to ignore time (i.e. publication and citation years) and set all the coefficients $t 1 \ldots t k$ to infinity, vector $\boldsymbol{\tau}_{u v}$ takes the form $\left(\left(c_{u, v}, b_{u, v}\right)^{1},\left(c_{u, v}, b_{u, v}\right)^{2}, \ldots,\left(c_{u, v}, b_{u, v}\right)^{k}\right)$ and Eq. (1) can be re-written as 


$$
\mathrm{R}(u)=\frac{1-d}{|A|}+d \sum_{(v, u) \in E} \mathrm{R}(v) \frac{\frac{w_{v, u}}{c_{v, u}+1} \sum_{v, u}+1}{b_{(v, j) \in E}} \frac{w_{v, k}}{\sum_{(v, k) \in E} \frac{c_{v, k}+1}{b_{v, k}+1} \sum_{(v, j) \in E} w_{v, j}},
$$

which is exactly how the time-unaware modifications of PageRank were defined by Fiala et al. (2008). These modifications penalized citations by colleagues (influence of $c$ ) but relaxed the penalty in some circumstances such as a great number of co-authors (influence of $b$ ). Now we can easily show how Eq. (2) can be further reduced to the standard PageRank formula. First, we set all $b$ 's to zero and take into account only the collaboration coefficients $c$ :

$$
\mathrm{R}(u)=\frac{1-d}{|A|}+d \sum_{(v, u) \in E} \mathrm{R}(v) \frac{\frac{w_{v, u}}{\left(c_{v, u}+1\right) \sum_{(v, j) \in E} w_{v, j}}}{\sum_{(v, k) \in E} \frac{w_{v, k}}{\left(c_{v, k}+1\right) \sum_{(v, j) \in E} w_{v, j}}} .
$$

Second, we disregard the co-authorship information by setting all $c$ 's to zero and obtain the weighted PageRank formula, in which the edges in the author citation graph $G$ are weighted with w's:

$$
\mathrm{R}(u)=\frac{1-d}{|A|}+d \sum_{(v, u) \in E} \mathrm{R}(v) \frac{\frac{w_{v, u}}{\sum_{(v, j) \in E} w_{v, j}}}{\sum_{(v, k) \in E} \frac{w_{v, k}}{\sum_{(v, j) \in E} w_{v, j}}} .
$$

And third, we set all the edge weights $w$ in $G$ to 1 and receive a standard PageRank formula which is equivalent to that by Brin and Page (1998):

$$
\mathrm{R}(u)=\frac{1-d}{|A|}+d \sum_{(v, u) \in E} \mathrm{R}(v) \frac{\frac{1}{D_{\text {out }}(v)}}{\sum_{(v, k) \in E} \frac{1}{D_{\text {out }}(v)}},
$$

where $d$ is the damping factor (set to 0.9 in our experiments) and $D_{\text {out }}(v)$ is the out-degree of vertex $v$. The damping factor represents the probability of following a link from the current node in the graph. Brin and Page (1998) set it to 0.85, Walker et al. (2007) recommend it to be 0.5 for publication citation networks. However, there is no consensus yet on what the damping factor should be in author citation graphs. 
The edge weights are pre-computed so the convergence of the PageRank modifications above does not differ from the standard PageRank (depending on $d$ ). In our experiments (see Section 5), the rankings became relatively stable after 20 to 30 iterations and we always continued to 50 iterations at most.

\subsection{Example}

In Figure 2 there is a simplified example of an author citation graph $E$ with four nodes $u, q, v$, $r$, three edges $(u, q),(u, v)$, and $(u, r)$. and three weight vectors $\boldsymbol{\tau}_{u q}, \boldsymbol{\tau}_{u v}$, and $\boldsymbol{\tau}_{u r}$ assigned to them. Fig. 2 should be placed here.

Now, let us suppose that $u$ cites $v$ three times, in 1980, 1990, and 2000. For the sake of simplicity, we will assume that all the coefficients $b$ are equal to zero, i.e. we will solely rely on the citations and collaborations between authors. We will consider two cases. In the first case, $c$ is 0 in 1980 (i.e., the number of common publications of $u$ and $v$ before 1980 was 0 ), 1 in 1990, and 2 in 2000. In the second case, $c$ is 2 in 1980, 1990, and 2000 (see Figure 3). The interpretation of the scenarios might be the following: when author $u$ first cited author $v$ in 1980, they did not know each other yet (scenario 1 on the left-hand side of Figure 3). When $u$ cited $v$ for the second time ten years later, they were colleagues already and had written one common publication in the meantime. At the time of the third citation in 2000, their coauthorship relation was even stronger because they already had two common publications (still scenario 1). This is quite different from scenario 2 on the right-hand side of Figure 3 , in which $u$ and $v$ probably know each other well in 1980 when $u$ cites $v$ for the first time as they already had two common publications at that time. However, they did not write any more articles together and their collaboration count $c$ remains unchanged in 1990 and 2000 when $u$ repeatedly cites $v$. If we ignore the citation years, the contribution (or weight) of the citations from $u$ to $v$ is $3 / 2$ in both scenarios, which is the nominator in Eq. (2) if all $b$ 's are 0. But, somehow, we feel that it is unjust and that the citation in 1980 should be weighted more if the authors do not know each other (left) than if they had already published together (right). Similarly, but perhaps less strictly, it happens in 1990 if the co-authorship relation between the authors is weaker (left) and stronger (right). Therefore, the co-authorship and other information entering the PageRank computation should always reflect the time of citation. This is exactly what we do in our time-aware PageRank modifications and formalize it in Eq. (1).

Fig. 3 should be placed here.

This is a preprint of the JOI submission. 
At the bottom of Figure 3, we can see the time-aware contributions of the individual citations. In 1980 the contribution is 1 (left) and $1 / 3$ (right), in 1990 it is $1 / 2$ (left) and $1 / 3$ (right), and, finally, in 2000 it is $1 / 3$ in both cases. Thus, the total weight of citations in scenario 1 is 11/6, almost twice as much as that in scenario 2 . Therefore, we may feel that the time-aware weighting has brought more justice to the prestige computation.

\section{Data}

To conduct practical experiments with the new evaluation method (time-aware PageRank), we needed to acquire some real-world data. For this purpose, we decided to download publication data from the Web of Science database, which is a well established data source for bibliometric studies. As we were only interested in the field of computer science, it was first necessary to determine the field boundaries. Since WoS does not enable the science domain to be specified in a straightforward way, we were forced to limit ourselves to publications appearing in journals classified as computer science sources. To compile such a list of relevant journals, in March 2011, we consulted the Journal Citation Reports ${ }^{\circledR}$ Science Edition 2009 (the most recent JCR at that time) in the following seven computer science subject categories: artificial intelligence, cybernetics, hardware $\&$ architecture, information systems, interdisciplinary applications, software engineering, and theory $\&$ methods. The list contained 426 journals whose names we could use in the search queries submitted programmatically to the WoS web services via their API. The time period we were interested in was the decade at the turn of the century: 1996 - 2005. Name changes of journals in that period were not taken into account. Unfortunately, the "lite" version of WoS web services does not allow the specifying of what document types are to be retrieved, nor is the document type information available in the documents retrieved. Therefore, we simply downloaded meta data from the Science Citation Index on all documents (of any type) published in those 426 journals in the years 1996 to 2005. In this way, we obtained 205780 "core" documents (strictly stated, their meta data such as title, authors, source, year, etc.). The next step was to find citations to these core documents from documents published up to December 31, 2010. To this end, we submitted further queries to WoS web services to determine citing documents for each individual core document. We found 1569057 citations from a total of 643302 citing documents. Of the citing documents, only 91728 were core documents for which all meta data were available. As a result, we were concerned with the analysis of 276957 citations between core documents. In the core documents themselves, there were 187016 different authors (disambiguated just by their surnames and given names' initials) with 1471312 This is a preprint of the JOI submission. 
citations between them (without self-citations). The results discussed in Section 5 are based on the author citation graph. Detailed statistics of the data retrieved from WoS will be given in a separate article.

The data collection we have chosen has an obvious limitation: it is biased towards computer scientists who prefer publishing their research in journals, although it is well known that computer science research is presented at conferences to a greater extent than other fields of science (Bar-Ilan, 2010; Franceschet, 2010; Wainer et al., 2011). On the other hand, computer science journal articles receive more citations on average than conference papers (Franceschet, 2010) and we can expect that with a growing pressure on the visibility of papers and a faster journal editorial process, both of which we have been witnessing in recent years, the need for publishing computer science research in journals will increase.

\section{Results and discussion}

Table 1 shows the standings of the top 50 researchers as calculated by the "basic" methods citation counts, in-degree, HITS, standard PageRank and weighted PageRank. By definition, citation counts are always greater or equal to in-degree. Since authors are not disambiguated, some names evidently represent more people with the same name as we can easily convince ourselves using a bibliographic database, e.g. in the case of "Jain, AK" or "Tanaka, K". On the other hand, some other names are apparently unique, e.g. "Kanade, T". The top authors by citations, in-degree, and HITS are very much the same with "Jain, AK", "Pentland, A", "Duin, RPW", and "Kanade, T" always appearing at the top. The interpretation of "Sapiro, G" being more highly ranked than "Kanade, T" in citations but more lowly ranked in in-degree is that "Sapiro, G" received more citations than "Kanade, T" but from fewer authors than "Kanade, T" did. Top-ranked authors by PageRank and by weighted PageRank are different from the first three rankings but similar to each other, with "Srinivasan, GR" and "Murley, PC" being at the very top.

Table 1 should be placed here.

\subsection{Time-aware versus time-unaware rankings}

As far as the rankings by the "advanced" methods (both time-aware and time-unaware) are concerned, the top 50 researchers in each ranking are shown in Tables A.1 to A.3 in the appendix. There are 14 rankings in total, with seven pairs of rankings, one of which is always the time-aware variant of the other: collaboration, publications, co-authors, distinct coThis is a preprint of the JOI submission. 
authors, all collaborations, all co-authors, and all distinct co-authors. The top-ranked authors by all methods are very much the same, e.g. with "Srinivasan, GR", "Murley, PC", and "Ziegler, JF" in high positions in each ranking. In fact, how similar are the individual rankings as a whole? Tables 2, 3, and 4 examine this aspect. In Table 2 we can see how the time-aware methods are correlated with each other. The table is symmetric and presents Spearman's rank correlation coefficients for each pair of time-aware rankings. The coefficients, which are all significant at the 0.01 level two-tailed, vary between 0.97 and 1 and suggest a very high correlation of all time-aware rankings. Similarly, very high Spearman's rank correlation coefficients can be observed in Table 3, which is non-symmetric and shows the correlation between time-aware and time-unaware PageRank variants. The most interesting figures are on the diagonal, where we can see how much new information is added if we use a time-aware variant instead of a standard PageRank modification. Provided that the lower the correlation achieved, the more new information is added using a time-aware method, the method taking into account all co-authors of an author prior to a citation (allCoauthorsT) instead of without regard to the citation time (allCoauthors) seems to work best. Table 4 is symmetric again. This time it shows how all the time-unaware rankings correlate with one another. The highest correlation can be observed with citations versus indegree (0.997), the lowest correlation with HITS versus allCoauthors (0.730). All in all, HITS is relatively less correlated (0.74) with all the PageRank-based methods, but it is very highly positively correlated (0.93) with both of the first-order methods - citations and in-degree. As for the PageRank variants, their correlation coefficients with citations and in-degree are all around 0.83 and they are quite close to each other with correlations about 0.99 . All the Spearman's rank correlation coefficients are significant at the 0.01 level two-tailed. The correlation between citations, in-degree, HITS, and (weighted) PageRank on the one side and the time-aware PageRanks on the other is not shown in Table 4, but the coefficients would be quite similar to those for the time-aware PageRanks regarding the high correlation between the time-aware and time-unaware rankings in Table 3.

Table 2 should be placed here.

Table 3 should be placed here.

Table 4 should be placed here. 


\subsection{ACM A. M. Turing Award winners}

In a further experiment, we wanted to compare the rankings obtained by the various methods with a "true" human-made baseline ranking of some kind. In the computer science domain, such a "ranking" can be made of the list of ACM A. M. Turing Award laureates. Even though the list of award winners is actually not a ranking, it enables one to compare computergenerated lists of authoritative researchers with the scientists considered prestigious by their peers and has been successfully used in several comparative studies in the past (e.g. Sidiropoulos and Manolopoulos, 2005 or Fiala et al., 2008). Table 5 shows the ranks of Turing Award winners from the years 1991 to 2010 (the past 20 years) produced by all of the 19 ranking methods described above. "Hartmanis, J" (1993), "Dahl, O" and "Nygaard, K" (2001), "Naur, P" (2005), and "Thacker, C" (2009) do not appear anywhere in the rankings and their rows are blank. The first two columns in Table 5 comprise citations and in-degree (the most frequently used research evaluation method) followed by HITS, PageRank, and weighted PageRank. Then there is a block of seven time-unaware PageRank modifications and a set of their seven time-aware counterparts. The ranks generated by the recursive techniques (from HITS onwards) were computed after fifty iterations (with the Spearman's rho between the rankings of two consecutive iterations being very close to 1 after just a few iterations) and are less important than the summary figures at the bottom of the table.

Table 5 should be placed here.

These numbers are the best rank, worst rank, average rank, medium rank, and standard deviation. Obviously, the lower the numbers the "better" the ranking in that it places the Turing Award winners higher (low ranks mean high positions). Therefore, an optimum ranking (with respect to the Turing Award) would place the awardees at ranks 1 to 23 (without those five researchers omitted) thus having a best rank of 1, worst rank of 23, average and median rank of 12 and a standard deviation of 6.63. Standard PageRank (in a darker column) achieves better indicators (except for the worst rank and standard deviation) than both citations and in-degree and much better than HITS, but its weighted variant does not seem to perform more efficiently. As far as the time-unaware PageRank modifications are concerned, their best ranks are better than citations or in-degree have but similar or worse than those of (weighted) PageRank. The same holds for the average rank and standard deviation. On the other hand, worst ranks and median ranks are almost always better than PageRank has. Approximately the same conclusions may be drawn for the time-aware 
modifications of PageRank with two exceptions: notably better average ranks were yielded by allCoauthorsT and especially by allDistCoauthors $T$, i.e. by the methods that take into account the number of all co-authors of both the citing and cited author prior to a citation. All in all, there are many better indicators than PageRank achieved and these are highlighted. There are more of them in the time-aware methods than in the time-unaware ones. (The ratio is 21 to 14.) A graphical representation of the results in Table 5 is displayed in Figure 4 (the award winners without ranks do not appear there).

Fig. 4 should be placed here.

In Figure 4 we can see a general slight shift towards better (lower) ranks when moving from left to right, i.e. from citations and in-degree across recursive methods and PageRank modifications to the time-aware variants of PageRank. This would suggest that the time-aware PageRank does reflect prestige perceived by humans (expressed by awards) better than common indicators such as citation counts or the standard PageRank and its weighted variations. Of course, there are some outliers in contradiction with this trend such as "Sifakis, $\mathrm{J}$ " and the sudden worsening of his rank with collaborationT and publicationsT or the overall bad performance of HITS for almost all of the authors, but this may also be interpreted as a feature of that particular ranking. For instance, the relatively bad ranks of "Sifakis, J" reveal that he has relatively frequently collaborated with the researchers citing him (both collaboration and collaborationT) and that he has written a great number of publications but rather after he was cited, thus having a good rank in publications and a bad rank in publicationsT. Some other authors, such as "Kay, A" or "Engelbart, D" are very badly ranked by almost all of the methods. This may be caused by the fact that they did not publish in journals in the time period under investigation. And indeed, they both have only three publications in our data set. But as we pointed out earlier, the individual ranks are less important and not discussed here than the overall trend, in which time-aware PageRanks seem to be closer to the "true" ranking than the other indicators.

\subsection{ACM SIGMOD E. F. Codd Innovations Award winners}

To bring additional evidence that would document the superiority of the time-aware methods over the time-unaware ones, we take advantage of yet another award - ACM SIGMOD E. F. Codd Innovations Award. The award winners from the years 1992 to 2011 are shown in Table 6 along with the ranks achieved in various rankings. ("Bayer, R" was not present in our data and, therefore, was not ranked.) Again, the ranks generated by the standard PageRank are 
in a darker column and the aggregate indicators yielded by both the time-unaware and timeaware rankings outperforming PageRank are highlighted. For instance, all seven worst ranks by time-aware methods outperform PageRank, but only one time-unaware worst rank does. In total, 24 time-aware indicators are better than PageRank compared to only 8 time-unaware ones. Also in Figure 5 we can see that allCoauthorsT and allDistCoauthorsT generally produce better ranks for the award winners. The worst ranked researchers, "Kitsuregawa, M" and "Selinger, P", published relatively few journal articles in the time period under study (14 and 3, respectively), but there is no such gap between them and the other laureates as in Figure 4.

Table 6 should be placed here.

Fig. 5 should be placed here.

The better performance of the time-aware methods over their time-unaware counterparts is further documented in Figures 6 and 7. In Figure 6, the solid blue lines represent best ranks (MIN), worst ranks (MAX), average ranks (AVG), median ranks (MED), and standard rank deviations (DEV) of the time-unaware (standard) PageRank modifications and the dashed red lines represent the time-aware PageRank variants. As for the Turing Award, three dashed lines are below their solid counterparts - MAX, DEV, and AVG. This means that from the point of view of these three indicators the time-aware methods outperform the time-unaware ones by generating lower (i.e. better) ranks for the awardees. As far as the Codd Award is concerned, even four indicators speak in favour of the time-aware methods - MAX, DEV, AVG, and MIN. The only indicator that is worse with both method types is the median rank (MED), which is, however, not very distinct as the solid and dashed lines lie close to each other. In Figure 7 box plots of the time-aware and time-unaware rankings are presented for each pair of rankings. In the case of both awards we can observe that the boxes of the timeaware rankings tend to be placed more towards lower (better) ranks than those of the timeunaware rankings.

Fig. 6 should be placed here.

Fig. 7 should be placed here. 


\section{Conclusions and future work}

Algorithms based on the recursive technique called PageRank (Brin and Page, 1998), which was first applied to the Web graph in order to determine the significance of Web pages, have been successfully used in many other situations since then. These methods enable one to evaluate nodes in any directed graphs and rank them according to their importance. In bibliometrics, citation networks of papers or authors, among others, can represent such directed graphs in which the nodes are papers (or authors) and the edges are citations between them. The prominence of researchers has long been detected by first-order methods such as simple citation counts, but it has been shown that popularity, not prestige, is often reflected by citation numbers. On the contrary, higher-order (recursive) methods such as PageRank are able to find prestigious actors that may have fewer citations but from prestigious sources. Also, PageRank-like ranking methods for bibliographic networks can take advantage of the additional information that is not present in a Web graph to weight edges in the network, e.g. co-authorship (Fiala et al., 2008) or time data (Walker et al., 2007, Yan and Ding, 2010, or Yu et al., 2004). Fiala et al. (2008) assigned different weights to the edges in a citation network of authors bearing in mind that a citation from a colleague was less valuable than that from a foreign researcher, but they did not distinguish whether the possible collaboration occurred before the citation was made or afterwards. In this article, we have made an attempt to remedy this situation. The main contributions of the research presented in this paper are as follows:

- We extended the model by Fiala et al. (2008) to incorporate the time of publications (and citations) in their "bibliographic PageRank" to create a "time-aware PageRank" for bibliographic networks. In this model, citations between researchers weight differently depending on a number of factors such as the number of common publications and whether or not they were published before a citation was made.

- We applied seven time-aware PageRank variants along with their time-unaware counterparts and five other common ranking methods (citations, in-degree, HITS, PageRank, and weighted PageRank) to the Web of Science data for computer science journal articles from the period 1996 - 2005 in order to find the most influential computer scientists publishing their work in journals in the decade at the turn of the century.

- We conducted a thorough correlation analysis of the time-aware rankings themselves as well as of the time-aware and time-unaware rankings and other bibliometrics measures such as citations or in-degree. We also compared all the 19 rankings with the 
lists of ACM A. M. Turing Award laureates from the years 1991 - 2010 and ACM

SIGMOD E. F. Codd Innovations Award winners from the years 1992 - 2011.

Based on our experiments, we achieved the following main results:

- All the 19 rankings are significantly highly positively correlated with each other. The very lowest correlation (around 0.74 of Spearman's rho) was found between HITS authorities and the other PageRank modifications. As for the new time-aware PageRanks, the lowest correlation (0.956), and thus the most added information when compared to its time-unaware counterpart, was observed between the variants in which the number of all co-authors in all publications of both the citing and cited authors are considered.

- The most prominent computer scientists contributing to WoS-indexed journals in the decade 1996 - 2005 detected by citations, in-degree, and HITS are "Jain, AK", "Pentland, A", and "Duin, RPW", whereas those determined by PageRank and all its variants are "Srinivasan, GR", "Murley, PC", and "Ziegler, JF".

- As far as the award winners are concerned, they generally receive better ranks in the time-aware rankings (as can be seen in Figures 4 and 5), but it is impossible to proclaim the "best" ranking because each individual ranking brings an improvement in some aspect (see Tables 5 and 6). However, compared to the standard (unweighted) PageRank in terms of several statistical indicators, the time-aware variants outperform the time-unaware ones (see Tables 5 and 6 and Figures 6 and 7).

For the time-aware PageRank modifications to be more effective, a greater citation window would probably be needed. This would result in a larger number of citations and collaborations of authors in different years. Then, the time-aware and time-unaware rankings should diverge from each other even more than in this study. Therefore, we would like to examine data spanning a greater time period in our future work on this promising topic. Other possibilities of adding more information to citations' weights would include investigating citation loops between authors and assigning less weight to the citations of authors who cite each other.

\section{Acknowledgements}

This work was supported by the European Regional Development Fund (ERDF), project "NTIS - New Technologies for Information Society", European Centre of Excellence, CZ.1.05/1.1.00/02.0090. The related software may be found at 
http://textmining.zcu.cz/downloads/tarank.php. Thanks are due to the anonymous reviewers for their insightful comments.

\section{References}

Bar-Ilan, J. (2010). Web of Science with the Conference Proceedings Citation Indexes: The case of computer science. Scientometrics, 83(3), 809-824.

Bergstrom, C. (2007). Eigenfactor: Measuring the value and prestige of scholarly journals. College and Research Libraries News, 68(5), 314-316.

Bollen, J., Rodriguez, M.A., \& Van De Sompel, H. (2006). Journal status. Scientometrics, 69(3), 669-687.

Brin, S., \& Page, L. (1998). The Anatomy of a Large-Scale Hypertextual Web Search Engine. In Proceedings of the 7th World Wide Web Conference, Brisbane, Australia, 107-117.

Chen, P., Xie, H., Maslov, S., \& Redner, S. (2007). Finding scientific gems with Google's PageRank algorithm. Journal of Informetrics, 1(1), 8-15.

Codd Award. http://www.sigmod.org/sigmod-awards/sigmod-awards\#innovations.

Ding, Y. (2011). Applying weighted PageRank to author citation networks. Journal of the American Society for Information Science and Technology, 62(2), 236-245.

Ding, Y., Yan, E., Frazho, A., \& Caverlee, J. (2009). PageRank for ranking authors in cocitation networks. Journal of the American Society for Information Science and Technology, 60(11), 2229-2243.

Fiala, D., Rousselot, F., \& Ježek, K. (2008). PageRank for bibliographic networks. Scientometrics, 76(1), 135-158.

Fiala, D. (2011). Mining citation information from CiteSeer data. Scientometrics, 86(3), 553562.

Fiala, D. (in press). Bibliometric analysis of CiteSeer data for countries. Information Processing and Management, doi:10.1016/j.ipm.2011.10.001.

Franceschet, M. (2010). The Role of Conference Publications in CS. Communications of the ACM, 53(12), 129-132.

González-Pereira, B., Guerrero-Bote, V.P., \& Moya-Anegón, F. (2010). A new approach to the metric of journals' scientific prestige: The SJR indicator. Journal of Informetrics, 4(3), 379-391.

Kleinberg, J. (1999). Authoritative Sources in a Hyperlinked Environment. Journal of the ACM, 46(5), 604-632. 
Ma, N., Guan, J., \& Zhao, Y. (2008). Bringing PageRank to the citation analysis. Information Processing and Management, 44(2), 800-810.

Sidiropoulos, A., \& Manolopoulos, Y. (2005). A citation-based system to assist prize awarding. SIGMOD Record, 34(4), 54-60.

Turing Award. http://awards.acm.org/homepage.cfm?srt=all\&awd=140.

Wainer, J., Goldenstein, S., \& Billa, C. (2011). Invisible Work in Standard Bibliometric

Evaluation of Computer Science. Communications of the ACM, 54(5), 141-148.

Walker, D., Xie, H., Yan, K.-K., \& Maslov, S. (2007). Ranking scientific publications using a model of network traffic. Journal of Statistical Mechanics: Theory and Experiment, 6, art. no. P06010.

Xing, W., \& Ghorbani, A. (2004). Weighted PageRank algorithm. In Proceedings of the 2nd Annual Conference on Communication Networks and Services Research, Fredericton,

Canada, 305-314.

Yan, E., \& Ding, Y. (2010). Weighted citation: An indicator of an article's prestige. Journal of the American Society for Information Science and Technology, 61(8), 1635-1643.

Yan, E., \& Ding, Y. (2011). Discovering author impact: A PageRank perspective. Information Processing and Management, 47(1), 125-134.

Yu, P.S., Li, X., \& Liu, B. (2004). On the Temporal Dimension of Search. In Proceedings of the 13th World Wide Web Conference, New York, USA, 1180-1181.

\section{Appendix A}

Table A.1 should be placed here.

Table A.2 should be placed here.

Table A. 3 should be placed here. 


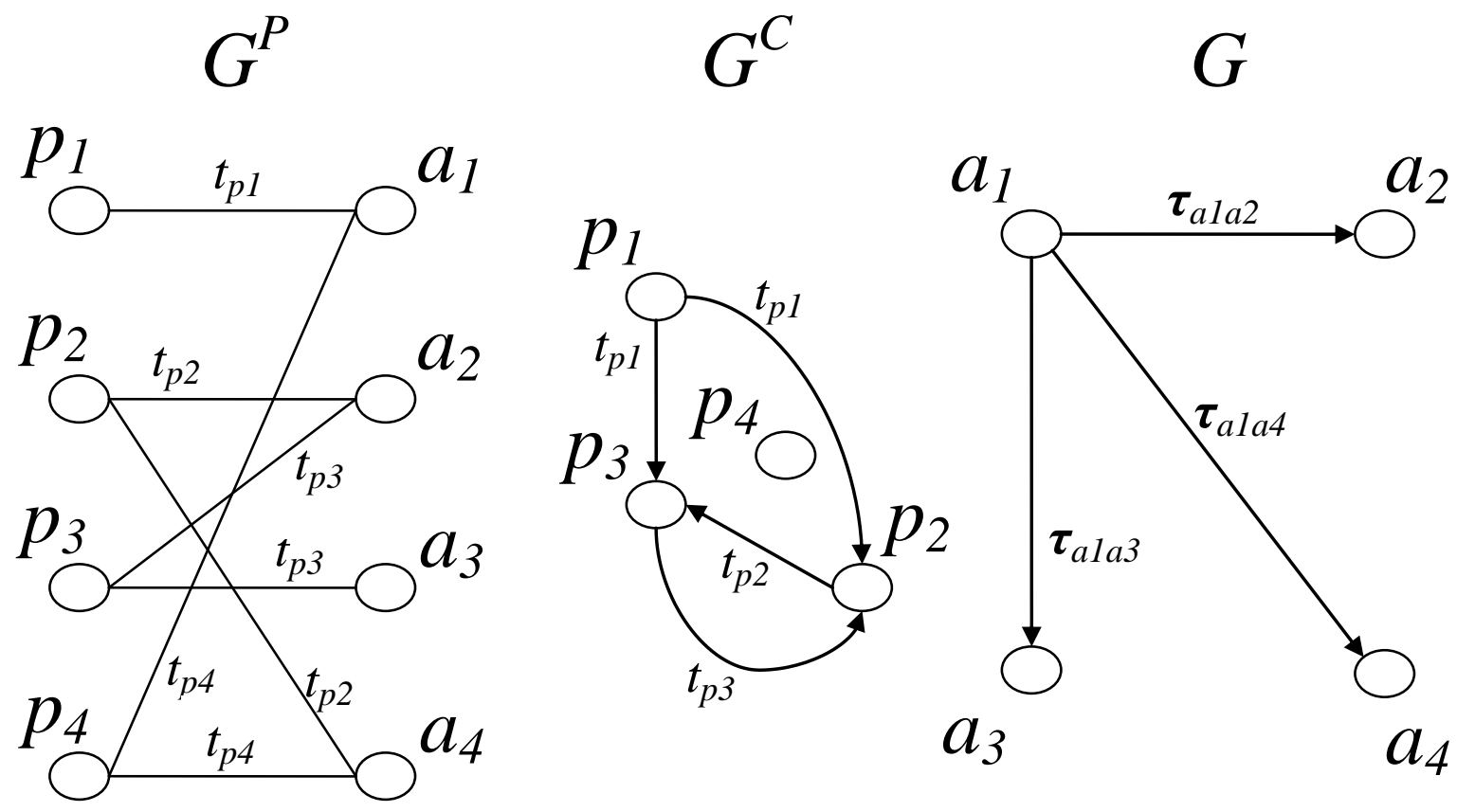

Fig. 1 Example of a co-authorship $\left(G^{P}\right)$, publication citation $\left(G^{C}\right)$, and author citation $(G)$ graph 


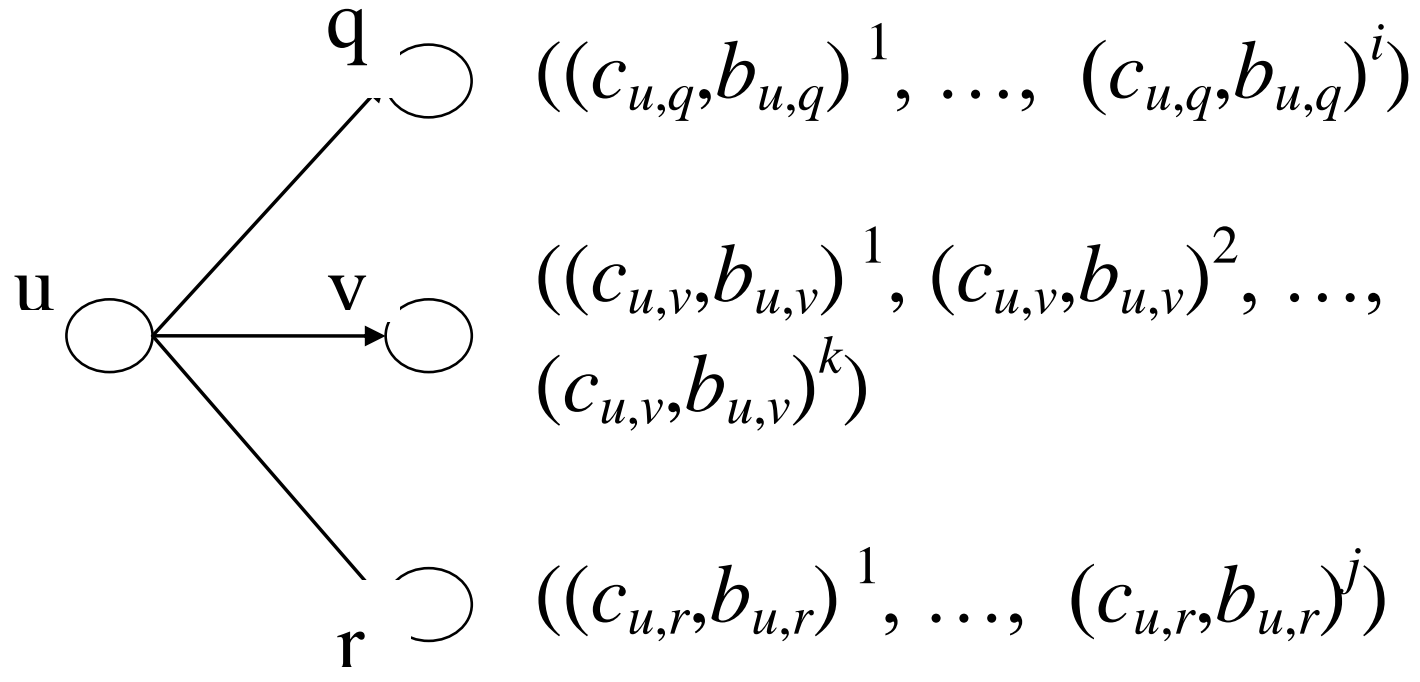

Fig. 2 Example of an author citation graph $E$ with weight vectors $\boldsymbol{\tau}$ 


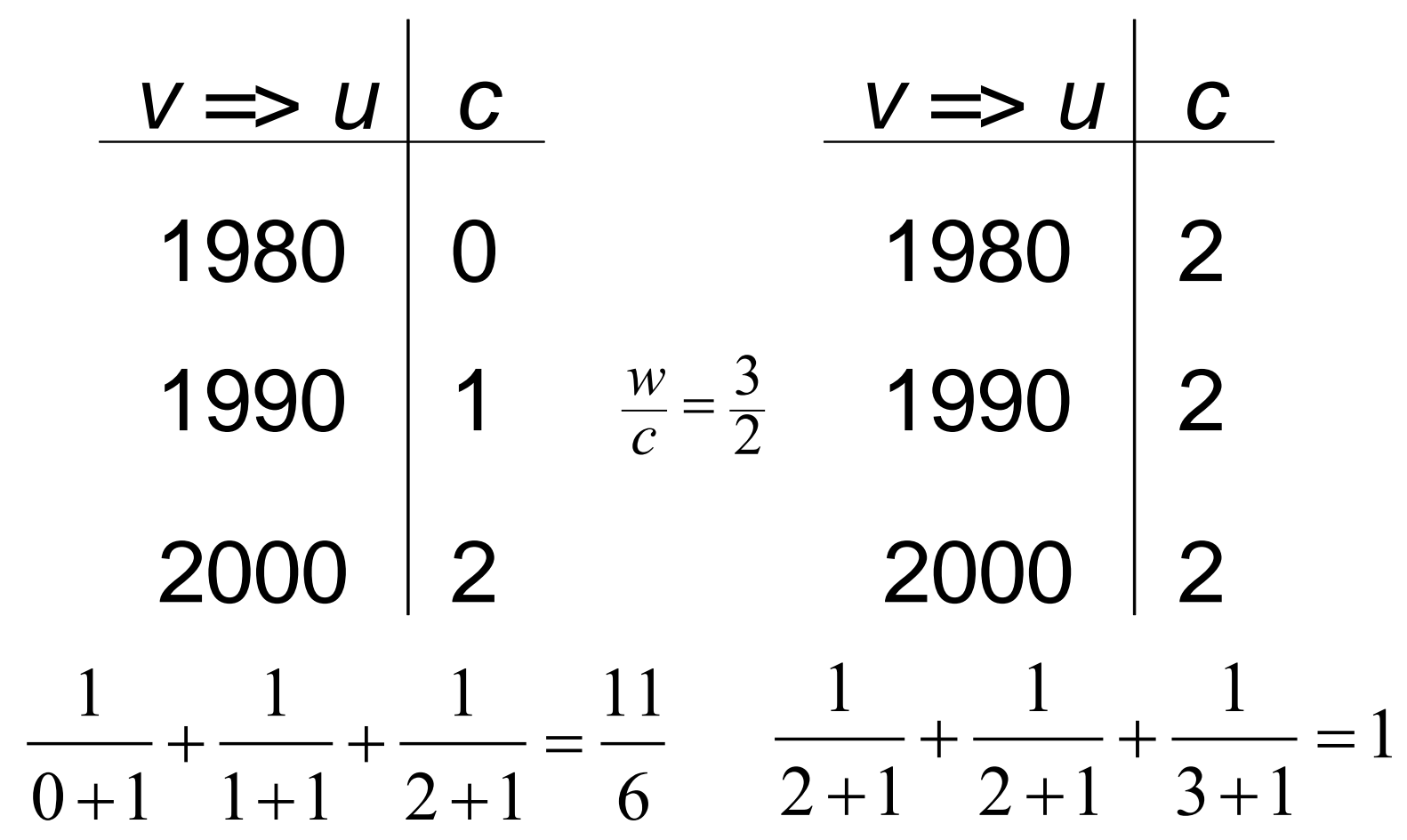

Fig. 3 Example of time-unaware (left) and time-aware (right) citation weighting 


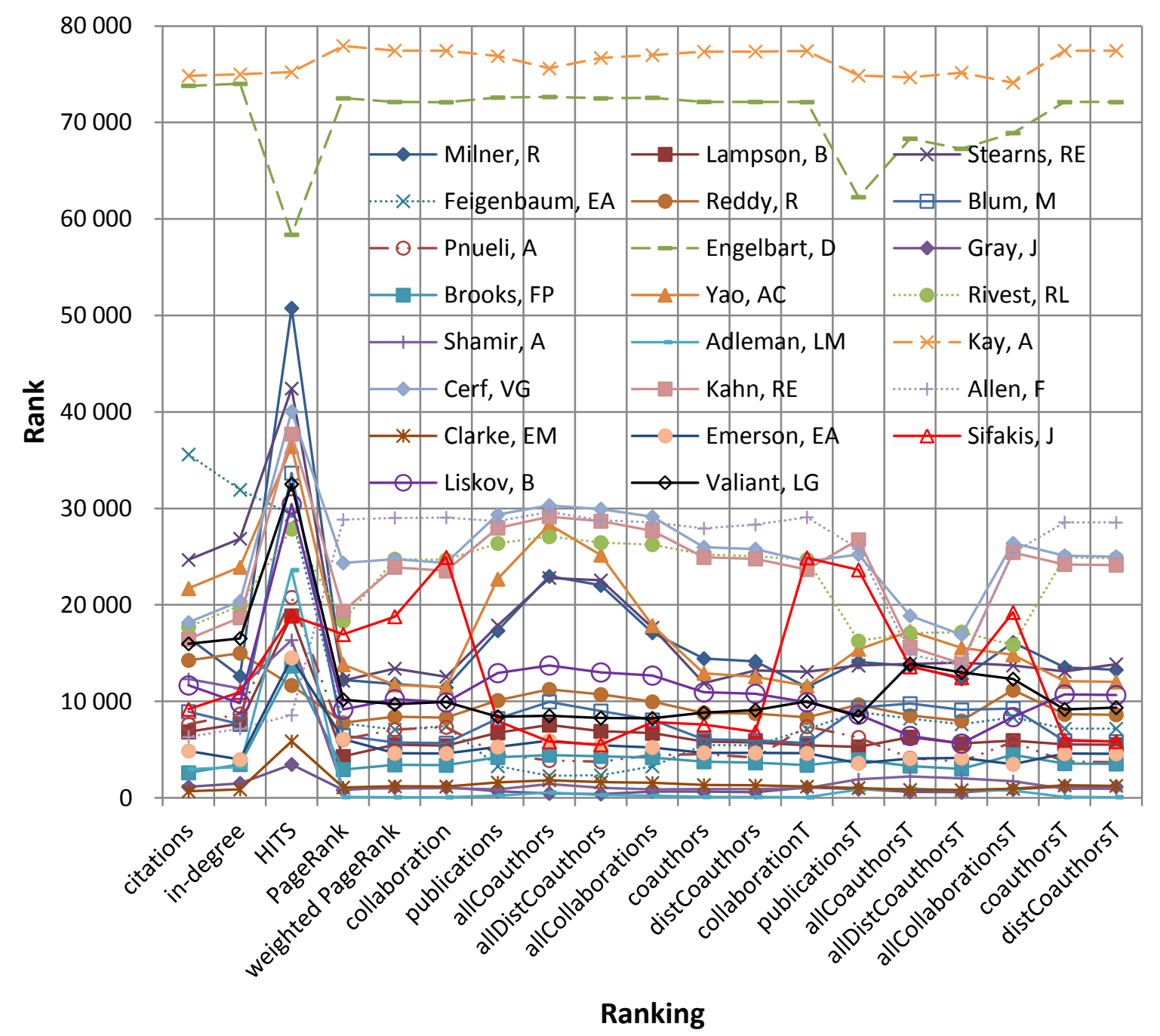

Fig. 4 ACM A. M. Turing Award winners and their ranks in different rankings 


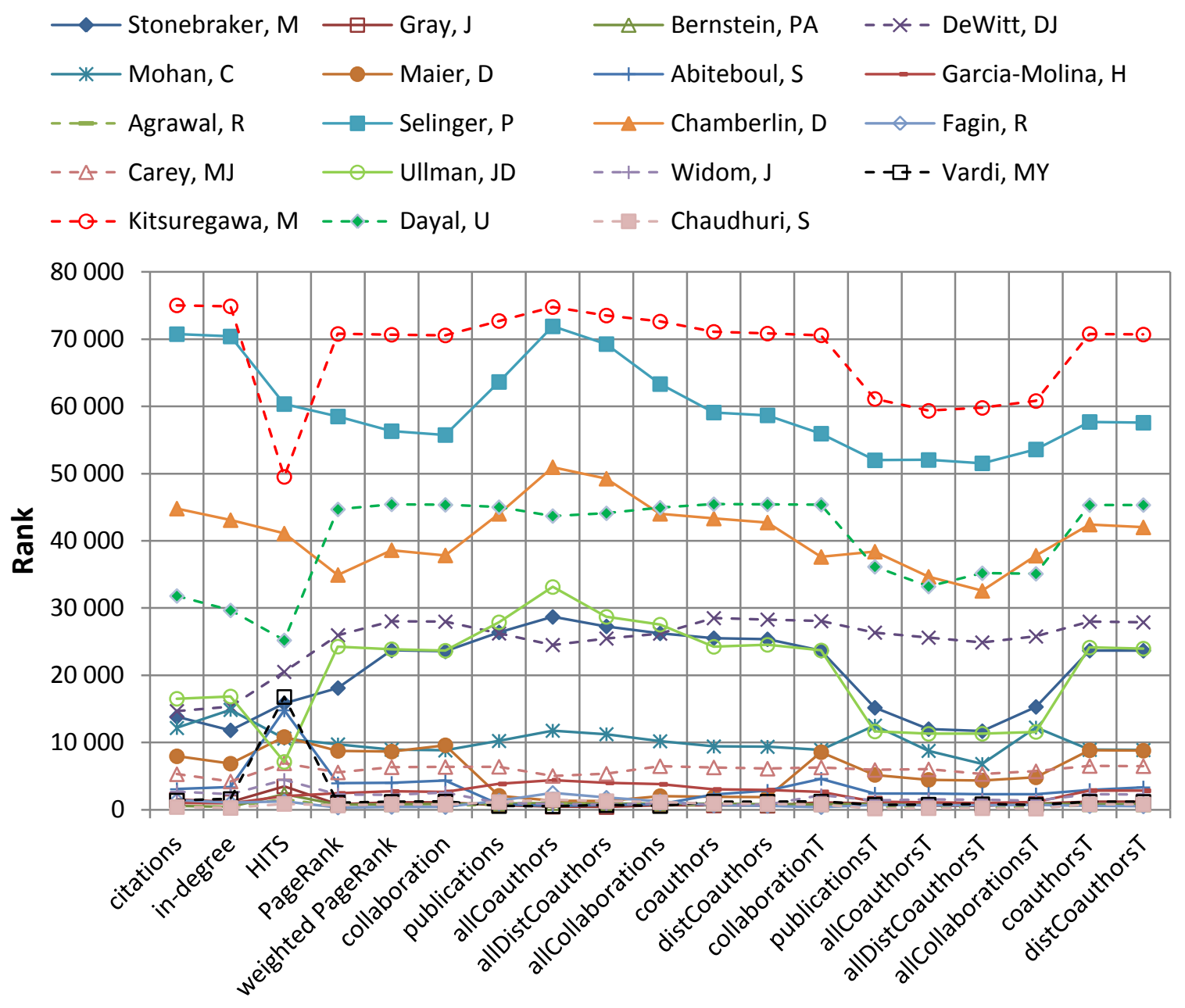

Ranking

Fig. 5

ACM SIGMOD E. F. Codd Innovations Award winners and their ranks in different rankings 

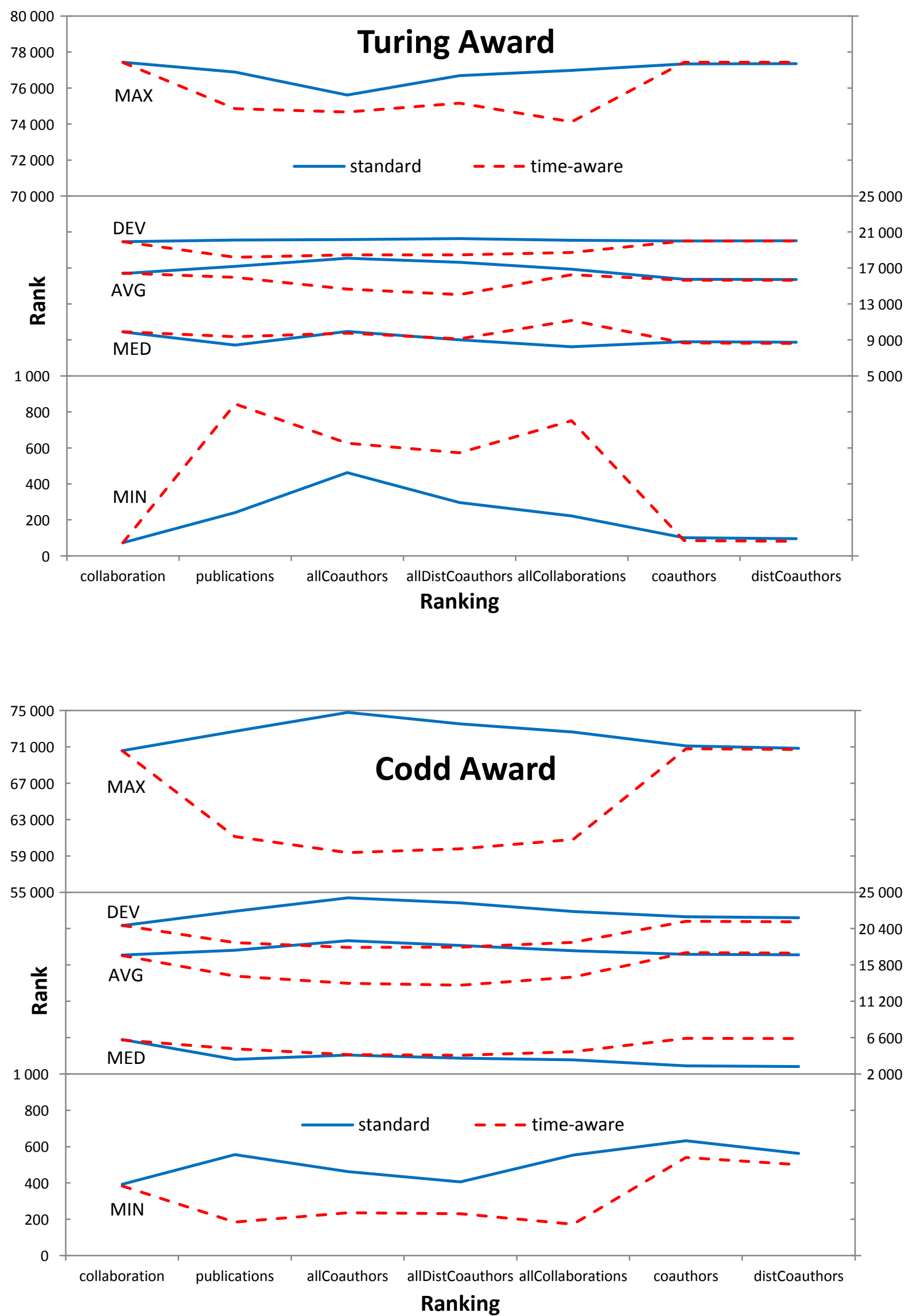

Fig. 6 Aggregate indicators of time-unaware (standard) and time-aware rankings

This is a preprint of the JOI submission. 


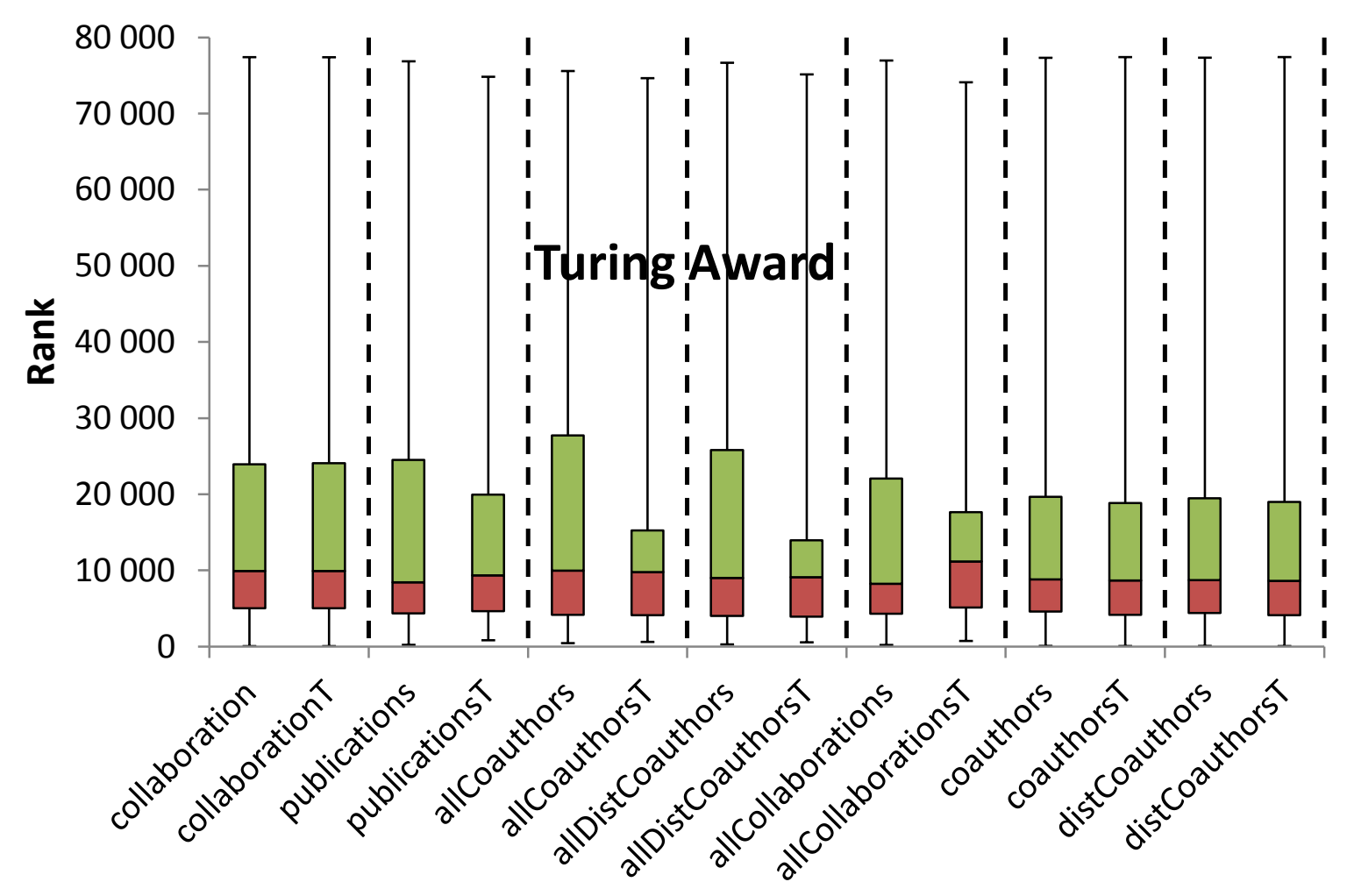

Ranking

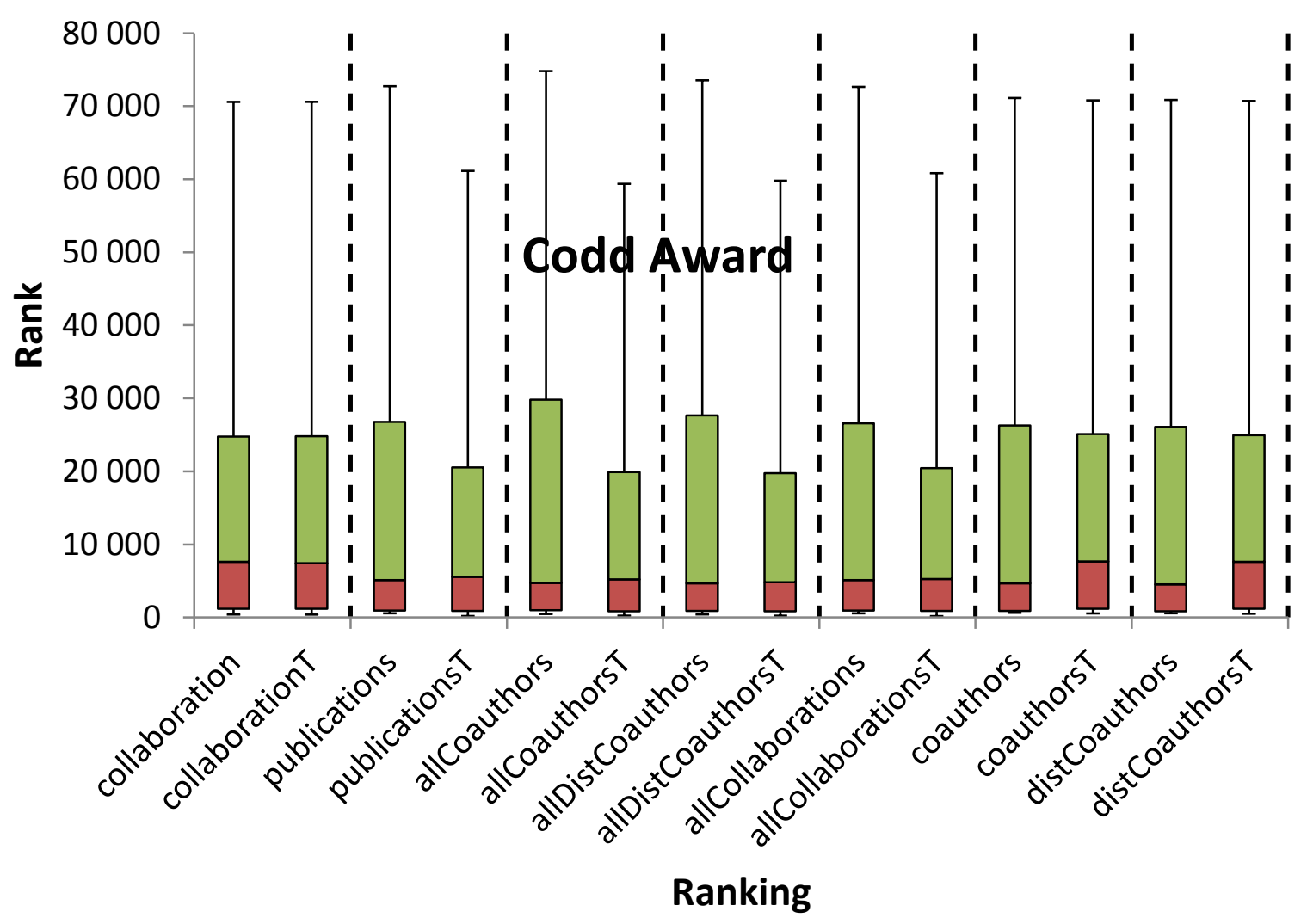

Fig. 7 Box plots of time-unaware and time-aware rankings 
Table 1 Top 50 researchers by citations, in-degree, HITS, and (weighted) PageRank

\begin{tabular}{|c|c|c|c|c|c|c|}
\hline \multicolumn{2}{|l|}{ Citations } & \multicolumn{2}{|l|}{ In-degree } & HITS & PageRank & Weighted PR \\
\hline \begin{tabular}{l|l}
1 & Jain, AK
\end{tabular} & 3103 & Jain, AK & 1912 & Jain, AK & Srinivasan, GR & Srinivasan, GR \\
\hline 2 Pentland, A & 1140 & Pentland, A & 851 & Pentland, A & Murley, PC & Murley, PC \\
\hline 3 Duin, RPW & 1103 & Duin, RPW & 769 & Belhumeur, PN & Tang, HHK & Ziegler, JF \\
\hline 4 Sapiro, G & 1036 & Kanade, $T$ & 757 & Duin, RPW & Freeman, LB & Freeman, LB \\
\hline $5 \mid$ Kanade, $T$ & 1026 & Gupta, A & 681 & Kriegman, DJ & Ziegler, JF & Tang, HHK \\
\hline 6 Tanaka, K & 1018 & Breiman, L & 636 & Kanade, $\mathrm{T}$ & Leinen, $\mathrm{P}$ & Leinen, $\mathrm{P}$ \\
\hline 7 Belhumeur, PN & 971 & Sapiro, G & 634 & Kikinis, $R$ & Bey, J & Bey, J \\
\hline $8 \mid$ Kriegman, DJ & 964 & Jain, $\mathrm{R}$ & 631 & Ayache, N & Juang, JG & Juang, JG \\
\hline 9 Scholkopf, B & 959 & Ayache, N & 624 & Jain, $\mathrm{R}$ & Juang, HG & Juang, HG \\
\hline 10 Breiman, L & 952 & Picard, RW & 624 & Smeulders, AWM & Korec, I & Curtis, HW \\
\hline 11 Viergever, MA & 937 & Belhumeur, PN & 623 & Kittler, J & Cegielski, $\mathrm{P}$ & Montrose, CJ \\
\hline 12 Kikinis, R & 933 & Viergever, MA & 602 & Maes, $\mathrm{F}$ & Wiener, $\mathrm{N}$ & Muhlfeld, HP \\
\hline 13Wang, $\mathrm{HO}$ & 933 & Kittler, J & 598 & Vandermeulen, D & Muses, C & OGorman, TJ \\
\hline 14 Osher, S & 920 & Kriegman, DJ & 596 & Sapiro, G & Litkowski, KC & Ross, JM \\
\hline 15 Bates, DW & 917 & Kikinis, R & 585 & Hespanha, JP & McTavish, DG & Korec, I \\
\hline 16 Hyvarinen, A & 896 & Scholkopf, B & 569 & Suetens, $\mathrm{P}$ & Gazarik, MJ & Wiener, $\mathrm{N}$ \\
\hline 17 Jain, R & 868 & Hyvarinen, $\mathrm{A}$ & 564 & Duncan, JS & Kamen, EW & Cegielski, $\mathrm{P}$ \\
\hline 18 Muller, KR & 868 & Cox, IJ & 562 & Wells, WM & Prou, JM & Taber, AH \\
\hline 19 Calderbank, AR & 866 & $Y u, P S$ & 560 & Viergever, MA & Wagneur, E & Walsh, JL \\
\hline 20 Tse, DNC & 866 & Lee, J & 558 & Picard, RW & Fidelman, U & Muses, C \\
\hline 21 Picard, RW & 86 & Muller, KR & 544 & Gupta, A & Ristow, GH & Litkowski, KC \\
\hline 22 Ayache, N & 855 & Huang, TS & 542 & Santini, S & Myers, JS & McTavish, DG \\
\hline 23 Gupta, A & 852 & Black, MJ & 530 & Huang, TS & Sampson, G & Gazarik, MJ \\
\hline 24 Kittler, J & 838 & Burges, CJC & 515 & Hawkes, DJ & Thomason, A & Kamen, EW \\
\hline 25 Yu, PS & 802 & Smeulders, AWM & 508 & Hill, DLG & Yngve, VH & Prou, JM \\
\hline $26 \mid$ Hill, DLG & 800 & Osher, S & 498 & Poggio, T & Behbehani, J & Wagneur, E \\
\hline 27|Bezdek, JC & 798 & Szeliski, R & 495 & Moghaddam, B & Robinson, DL & Renegar, J \\
\hline 28 Tarokh, V & 78 & Bates, DW & 489 & Worring, M & Schwarzer, S & Fidelman, U \\
\hline 29 Hawkes, DJ & 76 & Oja, E & 485 & Sclaroff, S & Wachmann, B & Ristow, GH \\
\hline 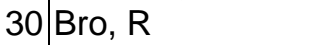 & 764 & Duncan, JS & 482 & Marchal, G & Wang, WY & Simon, DR \\
\hline 31 Black, MJ & 757 & Manjunath, BS & 481 & Manjunath, BS & Curtis, HW & Robinson, DL \\
\hline 32 Cox, IJ & 748 & Foster, I & 480 & Black, MJ & Montrose, CJ & Myers, JS \\
\hline 33 Duncan, JS & 733 & Zhu, SC & 479 & Zhu, SC & Muhlfeld, HP & Sampson, G \\
\hline 34|Shortliffe, EH & 729 & Santini, S & 476 & Collignon, A & OGorman, TJ & Thomason, A \\
\hline 35 Cimino, JJ & 717 & Suetens, $\mathrm{P}$ & 475 & Scholkopf, B & Ro & Yngve, VH \\
\hline 36 Shahar, $Y$ & 713 & Jain, A & 471 & Baluja, S & Taber, AH & Vazirani, U \\
\hline 37) Yager, RR & 712 & Flynn, PJ & 470 & Rowley, HA & Walsh, JL & Bernstein, $\mathrm{E}$ \\
\hline 38 Amari, S & 711 & Bezdek, JC & 465 & Mao, JC & Russell, CA & Schwarzer, S \\
\hline 39|Huang, TS & 710 & ר, S & 461 & Grimson, WEL & Chin, B & Wachmann, B \\
\hline 40|Suetens, P & 710 & Wells, WM & 459 & Prince, JL & Enger, TA & Wang, WY \\
\hline 41 Oja & 709 & Kim, J & 457 & Taylor, CJ & Hosier, $\mathrm{P}$ & Russell, CA \\
\hline 42 Musen, MA & 692 & Shortliffe, EH & 455 & Muller, KR & Klein, WA & Chin, B \\
\hline 43 Maes, $\mathrm{F}$ & 68 & Poggio, T & 453 & Jain, A & LaFave, LE & Enger, TA \\
\hline 44 Vandermeulen, D & 689 & Malik, J & 452 & Kimmel, $\mathrm{R}$ & Messina, B & Hosier, $\mathrm{P}$ \\
\hline 45Wells, WM & 685 & Schapire, RE & 452 & Cox, IJ & Nicewicz, M & Klein, WA \\
\hline 46 Kimmel, R & 68 & Sejnowski, TJ & 450 & Jolesz, FA & Orro, JM & LaFave, LE \\
\hline 47 Zhu, SC & 681 & Maes, F & 449 & Matas, J & Scott, TS & Messina, B \\
\hline 48 Lee, J & 668 & Vandermeulen, D & 449 & Vailaya, A & Sullivan, TD & Nicewicz, M \\
\hline 49 Jain, A & 66 & Kumar, V & 448 & Rueckert, D & Sussman, RJ & Orro, JM \\
\hline 50|Schapire, RE & 66 & Jennings, NR & 447 & Ma, WY & Sykes, AJ & Scott, TS \\
\hline
\end{tabular}

This is a preprint of the JOI submission. 
Table 2 Spearman's rank correlation coefficients of time-aware rankings

\begin{tabular}{|c|c|c|c|c|c|c|c|}
\hline & $\begin{array}{c}\text { collaboratio } \\
\mathrm{nT}\end{array}$ & $\begin{array}{l}\text { ublication } \\
\text { ST }\end{array}$ & $\begin{array}{c}\text { allCo- } \\
\text { authorsT }\end{array}$ & $\begin{array}{l}\text { allDistCo- } \\
\text { authorsT }\end{array}$ & $\begin{array}{c}\text { allCollabor } \\
\text { ationsT }\end{array}$ & $\begin{array}{c}\text { co- } \\
\text { authorsT }\end{array}$ & $\begin{array}{c}\text { distCo- } \\
\text { authorsT }\end{array}$ \\
\hline collaborationT & 1 & 0.975977 & 0.968838 & 3377 & 13 & 031 & 40 \\
\hline & $0.97 !$ & 1 & 951 & & & & \\
\hline & & 0.99 & 1 & 7 & & & \\
\hline all & & 0.990 & 0.99 & 1 & & & \\
\hline & & & & & & & \\
\hline & & 0.97 & 0.9 & & 0.9 & 1 & $99 s$ \\
\hline rsT & 0.999095 & 0.976147 & 0.969119 & 0.973527 & 0.975982 & 0.999905 & \\
\hline
\end{tabular}


Table 3 Spearman's rank correlation coefficients of both kinds of rankings

\begin{tabular}{l|ccccccc} 
& $\begin{array}{c}\text { collaboratio } \\
\text { nT }\end{array}$ & publication & allCo- & allDistCo- & allCollabor & co- & distCo- \\
& authorsT & authorsT & ationsT & authorsT & authorsT \\
\hline collaboration & $\mathbf{0 . 9 9 9 9 2 3}$ & 0.975964 & 0.968850 & 0.973384 & 0.975817 & 0.999022 & 0.999074 \\
publications & 0.993022 & $\mathbf{0 . 9 7 1 7 9 1}$ & 0.964273 & 0.968614 & 0.971584 & 0.994887 & 0.994677 \\
allCoauthors & 0.985647 & 0.963150 & $\mathbf{0 . 9 5 5 7 2 9}$ & 0.960214 & 0.963047 & 0.987923 & 0.987665 \\
allDistCoauthors & 0.990937 & 0.969841 & 0.962263 & $\mathbf{0 . 9 6 6 5 9 0}$ & 0.969608 & 0.993019 & 0.992810 \\
allCollaborations & 0.993664 & 0.972378 & 0.964848 & 0.969202 & $\mathbf{0 . 9 7 2 1 0 9}$ & 0.995404 & 0.995199 \\
coauthors & 0.998322 & 0.975931 & 0.968821 & 0.973308 & 0.975756 & $\mathbf{0 . 9 9 9 3 0 4}$ & 0.999151 \\
distCoauthors & 0.998737 & 0.975948 & 0.968946 & 0.973337 & 0.975784 & 0.999652 & $\mathbf{0 . 9 9 9 5 7 2}$
\end{tabular}


Table 4 Spearman's rank correlation coefficients of time-unaware rankings

\begin{tabular}{|c|c|c|c|c|c|c|c|c|c|c|c|c|}
\hline & Cites & InDeg & HITS & PR & $\begin{array}{c}\text { PR } \\
\text { weight } \\
\text { ed }\end{array}$ & $\begin{array}{l}\text { collab } \\
\text { oration }\end{array}$ & $\begin{array}{l}\text { public } \\
\text { ations }\end{array}$ & $\begin{array}{l}\text { allCoa } \\
\text { uthors }\end{array}$ & $\begin{array}{c}\text { allDist } \\
\text { Coaut } \\
\text { hors }\end{array}$ & $\begin{array}{c}\text { aborat } \\
\text { ons }\end{array}$ & $\begin{array}{l}\text { ti coauth } \\
\text { ors }\end{array}$ & $\begin{array}{c}\text { distCo } \\
\text { author } \\
\mathrm{s}\end{array}$ \\
\hline ites & 1 & 0.9973 & 0.9269 & 0.8353 & 0.8322 & 0.8318 & 0.8295 & 0.8235 & 0.8277 & 0.830 & 10.8322 & 20.8324 \\
\hline eg & 0.9973 & 1 & 0.9284 & 0.8364 & 0.8311 & 0. & 3 & 25 & 0.82 & $0.82 \varepsilon$ & 0.831 & 8313 \\
\hline TS & 0.9269 & 0.9284 & 1 & 0.7538 & 0.7448 & & & 01 & 0.7378 & 0. & 0. & 9.7450 \\
\hline PR & 0.8353 & 0.0004 & 0.7538 & 1 & 0.9956 & 0.9956 & & 331 & 0.988 & 0.5 & 60.994 & 50.9950 \\
\hline ahtod & 0.8322 & 0.8311 & 0.7448 & 0.9956 & 1 & 0.9998 & 0.9936 & 864 & 0.9916 & 0.9943 & 30.9987 & 70.9990 \\
\hline and & 0.8318 & 0.8308 & 0.7445 & 0.9956 & 0.9998 & 1 & 0.9928 & 853 & 0.990 & 0 & 0.9982 & 0.9986 \\
\hline iblicatio & 0.8295 & 0.8283 & 0.74 & 0.9900 & 0.9936 & 0.9928 & 1 & 0.9958 & 0.9989 & 0.9 & 70.9959 & 90.9956 \\
\hline $\begin{array}{l}\text { ICoauth } \\
\text { is }\end{array}$ & 0.8235 & 0.8225 & 0.7301 & 0.9831 & 0.98 & 0.985 & 0.9958 & 1 & 0.9972 & 0. & 00 & 40.9890 \\
\hline $\begin{array}{l}\text { allDistCoa } \\
\text { uthors }\end{array}$ & 0.8277 & 0.8266 & 0.7378 & 0.9880 & 0.9916 & 0.9906 & 0.9989 & 0.9972 & 1 & 0.9986 & 60 & 30.9939 \\
\hline $\begin{array}{l}\text { ICollabo } \\
\text { ations }\end{array}$ & 0.8301 & 0.8289 & 0.7415 & 0.9906 & 0.9943 & 0.9934 & 0.9997 & 0.9953 & 0.9986 & 1 & 0.9964 & 40.9961 \\
\hline coauthors & 0.8322 & 0.8311 & 0.7449 & 0.9945 & 0.9987 & 0.9982 & 0.9 & 0.989 & 0.9943 & 0.996 & 1 & 0.9996 \\
\hline $\begin{array}{l}\text { istCoaut } \\
\text { ors }\end{array}$ & 0 & 0 & 0 & 0. & 0 & 0. & $0 . c$ & 0 & 0.9 & 0.9 & 10.9996 & 1 \\
\hline
\end{tabular}


Table 5 ACM A. M. Turing Award winners (1991 - 2010) and their ranks

weight

ed

allDist allColla

distCo

allCoa allDist allColl

distCo

citatio in- PageR PageR collabo publica allCoa Coauth borati coauth author collabo publica uthors Coauth aborati coauth author

Year Winner orsT onsT orsT ST

1991 Milner, R $165901261250753122341181411428173352296422025171231443714152 \quad 11488140801368212330161131352713274$

1992 Lampson, B 1993 Hartmanis, J

1993 Stearns, RE

1994 Feigenbaum, \begin{tabular}{lllllllllllll|llllllll}
6842 & 7698 & 18864 & 4295 & 5504 & 5407 & 6744 & 7556 & 6901 & 6701 & 5839 & 5736 & 5438 & 5294 & 6299 & 5628 & 5946 & 5551 & 5517
\end{tabular}

$246682686442424121481340012562178782279622549176351188313196 \quad 13058137111387714027137181310213862$ $\begin{array}{llllllllllllllllllll}1994 \text { Reddy, R } & 1425714998 & 11659 & 7786 & 8412 & 8309 & 10095 & 11248 & 10713 & 9961 & 8805 & 8744 & 8335 & 9652 & 8526 & 7990 & 11168 & 8659 & 8621\end{array}$

$\begin{array}{lllllllllllllllllllllll}8934 & 7618 & 33665 & 6456 & 5745 & 5682 & 8227 & 9954 & 9004 & 8086 & 6058 & 5956 & 5656 & 9367 & 9769 & 9120 & 9255 & 5913 & 5830\end{array}$ 1996 Pnueli, A 1997 Engelbart, D 1998 Gray, J 1999 Brooks, FP 2000 Yao, AC 2001 Dahl, O 2001 Nygaard, $K$ 2002 Rivest, RL 2002 Shamir, A 2002 Adleman, LM 2003 Kay, A 2004 Cerf, VG 2004 Kahn, RE 2005 Naur, $P$ 2006 Allen, F 2007 Clarke, EM 2007 Emerson, EA 2007 Sifakis, J 2008 Liskov, B 2009 Thacker, C

2010 Valiant, LG

Best rank

Worst rank

\begin{tabular}{rlrl|l|llllllll|lllllll}
7631 & 870420785 & 6062 & 7066 & 7324 & 4522 & 3879 & 3738 & 4448 & 4515 & 4178 & 7395 & 6269 & 4127 & 3748 & 5803 & 3770 & 3689
\end{tabular} 73807740095836772511721297210872588726517250572569721397213372115622656832767279689127211772117

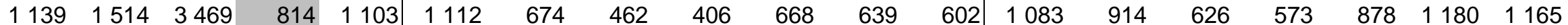
\begin{tabular}{llllll|llllllll|llllll}
2609 & 3459 & 13669 & 2937 & 3429 & 3376 & 4194 & 4435 & 4294 & 4177 & 3747 & 3646 & 3386 & 3956 & 3294 & 2997 & 4479 & 3553 & 3519
\end{tabular} 21696239113641013812117111148722671283402516517860129161255811604153981725915557148271208512018

17719199122785718337247452468226376270772645426254252282503824697162651708117190158472492624824 \begin{tabular}{llllllllllll|lllllll}
12309 & 11345 & 16354 & 978 & 971 & 1027 & 876 & 1448 & 1043 & 873 & 926 & 914 & 1010 & 1916 & 2222 & 2032 & 1725 & 941 & 939
\end{tabular}

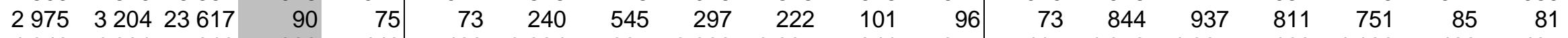
74842749917521077939774427742876884756077668976985773417735777415748527466775163741267743377437 18173203724005224344247382435429368303132993729143259712579224510252351888216927263932509124993 16450186723770219355239062352127978291552867927675249202477623676267551564313908254372419724130

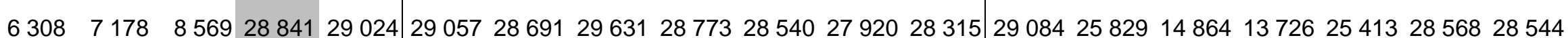

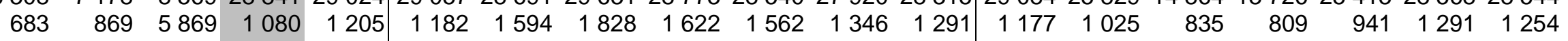
$\begin{array}{lllllllllllllllllllll}4859 & 3974 & 14513 & 6082 & 4627 & 4604 & 5282 & 5932 & 5451 & 5226 & 4666 & 4659 & 4625 & 3582 & 4083 & 4133 & 3480 & 4595 & 4577\end{array}$ $\begin{array}{llllllllllllllllllll}9186 & 10953 & 18865 & 16937 & 18788 & 24930 & 7965 & 5824 & 5504 & 7855 & 7581 & 6832 & 24880 & 23630 & 13580 & 12455 & 19228 & 5985 & 5844\end{array}$ $11662980230434 \quad 916510230 \quad 9902129361373213007126861094210790 \mid 9914 \quad 8631 \quad 6424 \quad 563283811072510653$

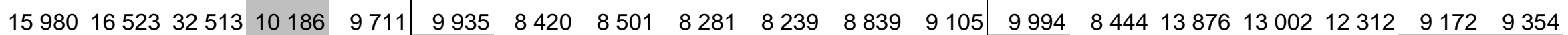

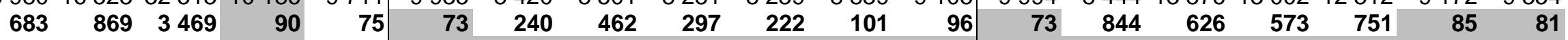
$\begin{array}{ll}748427499175210779397744277428768847560776689769857734177357 & 77415748527466775163741267743377437\end{array}$ $1760517875283041565816211 \quad 1638817166180931762616859157491570916423159491465714029162381563715627$

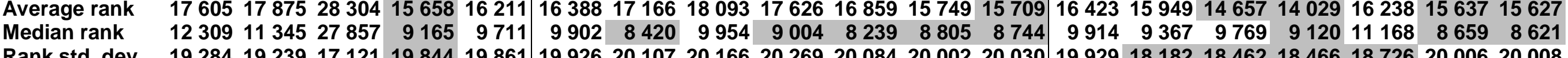
Rank std. dev.

19284192391712119844198611992620107201662026920084200022003019929181821846218466187262000620008 
Table 6 ACM SIGMOD E. F. Codd Innovations Award winners and their ranks

weight

allDist allColla distCo

allCoa allDist allColla

distCo

citation in- $\quad$ PageR PageR collabo publica allCoa Coauth boratio coauth author collabo publica uthors Coauth boratio coauth author

\begin{tabular}{|c|c|c|c|c|c|c|c|c|c|c|c|c|c|c|c|c|c|c|c|}
\hline 'ear Win & $\mathrm{s}$ & degree & HITS & ank & ank & ration & tions & thors & ors & ns & ors & & tinn & $\mathrm{nsT}$ & & orsT & nsT & orsT & \\
\hline 1992 Stonebraker, M & 13816 & 11821 & 15821 & 18112 & 23700 & 23559 & 26392 & 28690 & 27276 & 6242 & 5528 & 5366 & 23671 & 5176 & 997 & 690 & 30 & 7 & 36 \\
\hline 1993 Gray, J & 1514 & 1139 & 3469 & 814 & 1103 & 1112 & 674 & 462 & 406 & 668 & 639 & 602 & 1083 & 914 & 626 & 573 & $87 \xi$ & 180 & \\
\hline stein, PA & 560 & 429 & 2301 & 758 & 808 & 828 & 904 & 990 & 895 & 912 & 877 & 818 & 818 & 849 & 845 & 848 & 88 & 807 & \\
\hline & 14670 & 15354 & 20509 & 25963 & 28031 & 27983 & 26237 & 24510 & 25481 & 26211 & 28510 & 28296 & 28058 & 26351 & 25610 & 24888 & 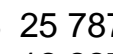 & 27985 & \\
\hline , C & 12167 & 14863 & 10582 & 9724 & 8948 & 8832 & 10235 & 11758 & 11237 & 10188 & 9415 & 9371 & 8908 & 12515 & 8763 & 6809 & 1222 & 8926 & \\
\hline D & 7954 & 6859 & 10832 & 8760 & 8655 & 595 & 2077 & 1350 & 1290 & 2032 & 1936 & 1847 & 8 & 5184 & 4445 & 57 & 482 & & \\
\hline oul, S & 3054 & 3348 & 14794 & 3934 & 3986 & 4361 & 795 & & 722 & 820 & 2271 & 2817 & 4602 & 2391 & 2386 & 16 & 28 & & \\
\hline lolina, $\mathrm{H}$ & 1007 & 936 & 2003 & 2442 & 2720 & 2654 & 3842 & 4395 & 4010 & 3790 & 024 & 2929 & 2659 & 205 & 070 & 009 & 3 & 58 & \\
\hline $\mathrm{R}$ & 533 & 395 & 1592 & 458 & 569 & 551 & 807 & 955 & 819 & 789 & 633 & 610 & 553 & 419 & 414 & 323 & 3 & 86 & \\
\hline
\end{tabular}

2000 Agrawal, R

2001 Bayer, $\mathrm{R}$

2002 Selinger, $P$

2003 Chamberlin, D

70765704206036458514563305575963652719226928863339591055867855958519985204351543536085770157587 $4481043091410953493538619 \quad 37837440335096949257440384333642732 \quad 37616384013466232568378004243342013$

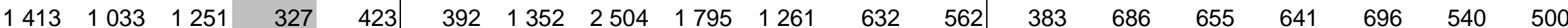

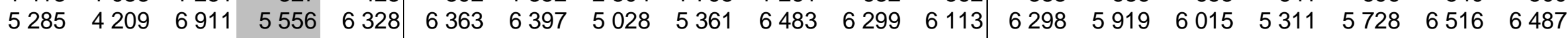
$1651816855 \quad 71182427123886 \quad 2366427892331442870127544242462454123699116471129511307115802413223972$

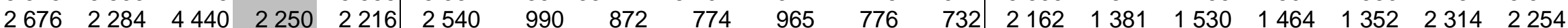

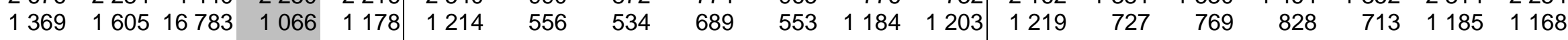
$7505074905495297079770681 \quad 7057672726748007353672636711087085270590611265935859795608207079270707$ $3180629660252044469145438 \quad 4536845022437044410644948454634543645389361503321235192351054532145339$ 2005 Carey, MJ 2007 Widom, J 2008 Vardi, MY 2009 Kitsuregawa, M 2010 Dayal, U

2011 Chaudhuri, S

Best rank

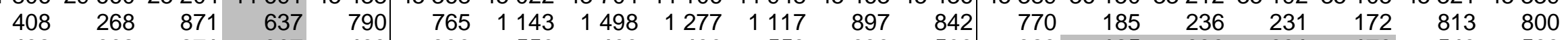
Worst rank Average rank

Median rank

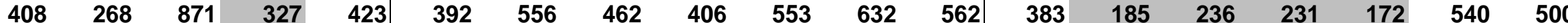

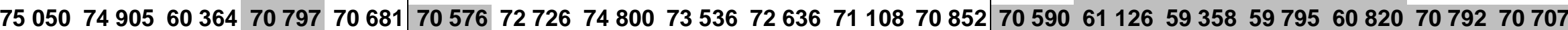

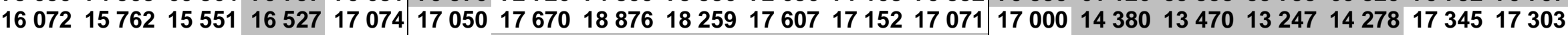
\begin{tabular}{lllllll|l|llllllllllll}
5285 & 4209 & 10582 & 5556 & 6328 & 6363 & 3842 & 4395 & 4010 & 3790 & 3024 & 2929 & 6298 & 5184 & 4445 & 4357 & 4826 & 6516 & 6487
\end{tabular}

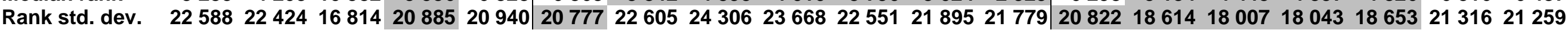


Table A.1 Top 50 researchers by both kinds of rankings (part 1)

\begin{tabular}{|c|c|c|c|c|c|c|}
\hline & collaboration & collaboration I & & puidilc & allu & allCoauthors I \\
\hline 1 & Srinivasan, GR & Srinivasan, GR & Srinivasan, GR & Srinivasan, GR & Sudan, M & Srinivasan, GR \\
\hline 2 & Murley, PC & Murley, PC & Ziegler, JF & Jain, AK & Ziegler, JF & Murley, PC \\
\hline 3 & Tang, HHK & Ziegler, JF & Verdu, S & Murley, PC & Verdu, S & Jain, AK \\
\hline 4 & Freeman, LB & Freeman, LB & Sudan, M & Ziegler, JF & Srinivasan, GR & Ziegler, JF \\
\hline 5 & Ziegler, JF & Tang, HHK & Shamai, S & Freeman, LB & Sapiro, G & Freeman, LB \\
\hline 6 & Leinen, $\mathrm{P}$ & Leinen, $\mathrm{P}$ & Murley, PC & Tang, HHK & Osher, S & Tang, HHK \\
\hline 7 & Bey, J & Bey, J & Freeman, LB & Sudan, M & Shamai, S & Sudan, M \\
\hline 8 & Juang, JG & Juang, JG & Tse, DNC & Shamai, S & Jain, AK & Calderbank, AR \\
\hline 9 & Juang, HG & Juang, HG & Jain, AK & Tse, DNC & Tse, DNC & Renegar, J \\
\hline 10 & Korec, I & Korec, I & Osher, S & Calderbank, AR & Bartlett, PL & Shamai, S \\
\hline 11 & Curtis, HW & Curtis, HW & Sapiro, G & Cimino, J J & Lin, YB & Pentland, A \\
\hline 12 & Montrose, CJ & Montrose, CJ & Tarokh, V & Pentland, A & Kschischang, FR & Tse, DNC \\
\hline 13 & Muhlfeld, HP & Muhlfeld, HP & Vardy, A & Kanade, $\mathrm{T}$ & Cimino, JJ & Osher, S \\
\hline 14 & OGorman, TJ & OGorman, TJ & Kschischang, FR & Breiman, L & Vardy, A & Sapiro, G \\
\hline 15 & Ross, JM & Ross, JM & Tang, HHK & Tarokh, V & Shortliffe, EH & Cimino, JJ \\
\hline 16 & Wiener, N & Wiener, N & McEliece, RJ & Sapiro, G & Scholkopf, B & Gupta, A \\
\hline 17 & Cegielski, P & Cegielski, P & Cimino, JJ & Sejnowski, TJ & Bates, DW & Sejnowski, TJ \\
\hline 18 & Taber, AH & Taber, $\mathrm{AH}$ & Leinen, $\mathrm{P}$ & Gur & ece, RJ & ver, MA \\
\hline 19 & Walsh, JL & Walsh, JL & Lapidoth, A & Verdu, S & Tarokh, V & Kikinis, R \\
\hline 20 & Muses, C & Muses, C & Arora, S & Lee, J & Arora, S & Kanade, T \\
\hline 21 & Litkowski, KC & Litkowski, KC & Oja & Osh & Bro, R & Tarokh, V \\
\hline 22 & McTavish, DG & McTavish, DG & Schapire, RE & Leinen, $\mathrm{P}$ & Duin, RPW & Lee, J \\
\hline 23 & , MJ & rik, MJ & $t t, P L$ & Jain & Oja, E & ire, $R E$ \\
\hline 24 & Kamen, EW & Kamen, EW & Mesiar, R & Jordan, MI & Zuckerman, D & Yu, \\
\hline 25 & Prou, JM & Prou, JM & Yager, RR & Yu, & Lapidoth, A & $\mathrm{d}, \mathrm{RM}$ \\
\hline 26 & Wagneur, E & $\mathrm{ur}, \mathrm{E}$ & Bro, R & ever, MA & $\mathrm{tta}, \mathrm{TL}$ & Alo \\
\hline 27 & Ristow & $\mathrm{GH}$ & Marzetta, TL & ay, DJC & Mesiar, R & $\mathrm{Am}$ \\
\hline 28 & , U & ר, U & GD & & ge, JM & i, R \\
\hline 29 & Simon & Sim & Zuckerman, D & re, RE & nan, LB & DW \\
\hline 30 & Renegar, J & Renegar, J & Bey, J & $\mathrm{Am}$ & Schapire, RE & nald, CJ \\
\hline 31 & Robins & n, DL & th, MK & Alo & $y, G D$ & Jor \\
\hline 32 & Myers, JS & Mye & liffe, EH & Vardy, A & $\operatorname{ar}, \mathrm{Y}$ & Verc \\
\hline 33 & son, $\mathrm{G}$ & son, $G$ & opf, B & Feig & Shu, CW & n, $V$ \\
\hline 34 & Thomason, A & Thomason, A & eth, T & Richardson, TJ & Kimmel, R & Var \\
\hline 35 & Yngve & e, $\mathrm{VH}$ & & Bey & Musen, MA & Jair \\
\hline 36 & Vaz & i, U & An & Mo & $\mathrm{RR}$ & -G \\
\hline 37 & Bernstein, E & Bernstein, E & Sha & ch, $\mathrm{O}$ & Smola, AJ & opf, B \\
\hline 38 & Wang, WY & Schwarzer, S & RPW & $\mathrm{Re}$ & Warmuth, MK & $\mathrm{KR}$ \\
\hline 39 & zer, S & Wachmann, B & ald, BM & Sze & Am & Ros \\
\hline 40 & Wachmann, B & Wang, WY & Kim & d, RW & Williamson, RC & HW \\
\hline 41 & ell, CA & Ill, CA & MI & Kit & M & se, CJ \\
\hline 42 & Chin, B & Chi & PM & tt, $\mathrm{PL}$ & Linder, $\mathrm{T}$ & eld, HP \\
\hline 43 & Enger, TA & $r, \mathrm{TA}$ & Calderbank, AR & $n, V$ & Helleseth, $\mathrm{T}$ & an, TJ \\
\hline 44 & Hosier, P & Hosier, $\mathrm{P}$ & son, DP & nen, $A$ & , W & $\mathrm{PL}$ \\
\hline 45 & Klein, WA & Klein, WA & Shahar, Y & Sharir, M & Campbell, KE & Lein \\
\hline 46 & LaFave, LE & LaFave, LE & Freund, Y & Hochwald, BM & Chlamtac, I & bley, D \\
\hline 47 & Messina, B & Messina, B & Shu, CW & Tanaka, K & Jordan, MI & Kim, J \\
\hline 48 & Nicewicz, M & Nicewicz, M & Renegar, J & Black, MJ & Greenes, RA & Willinger, W \\
\hline 49 & Orro, JM & Orro, JM & Szegedy, M & Arora, S & Williamson, DP & CG \\
\hline 50 & Scott, TS & Scott, TS & Maass, W & Kim, J & Fang, YG & Breiman, L \\
\hline
\end{tabular}


Table A.2 Top 50 researchers by both kinds of rankings (part 2)

\begin{tabular}{|c|c|c|c|c|}
\hline & allDistCoauthors & allDistCoauthorsT & allCollaborations & allCollaborationsT \\
\hline 1 & Ziegler, JF & Srinivasan, GR & Srinivasan, GR & Srinivasan, GR \\
\hline 2 & Srinivasan, GR & Murley, PC & Ziegler, JF & Jain, AK \\
\hline 3 & Sudan, M & Ziegler, JF & Verdu, S & Murley, PC \\
\hline 4 & Freeman, LB & Freeman, LB & Sudan, M & Ziegler, JF \\
\hline 5 & Osher, S & Tang, HHK & Murley, PC & Freeman, LB \\
\hline 6 & Sapiro, G & Jain, AK & Shamai, S & Tang, HHK \\
\hline 7 & Verdu, S & Sudan, M & Freeman, LB & Sudan, M \\
\hline 8 & Shamai, S & Renegar, J & Jain, AK & Shamai, S \\
\hline 9 & Jain, AK & Calderbank, AR & Tse, DNC & Tse, DNC \\
\hline 10 & Tse, DNC & Pentland, A & Osher, S & Renegar, J \\
\hline 11 & Kschischang, FR & Shamai, S & Sapiro, G & Calderbank, AR \\
\hline 12 & McEliece, RJ & Gupta, A & Tang, HHK & Tarokh, V \\
\hline 13 & Tarokh, V & Tse, DNC & Tarokh, V & Kanade, $\mathrm{T}$ \\
\hline 14 & Arora, S & Freund, RM & Vardy, A & Pentland, A \\
\hline 15 & Vardy, A & Sapiro, G & Kschischang, FR & Cimino, JJ \\
\hline 16 & Cimino, JJ & Kanade, $\mathrm{T}$ & McEliece, RJ & Sapiro, G \\
\hline 17 & Zuckerman, D & Alon, N & Leinen, $\mathrm{P}$ & Sejnowski, TJ \\
\hline 18 & Bates, DW & Sejnowski, TJ & Cimino, JJ & Osher, S \\
\hline 19 & Shortliffe, EH & Lee, J & Arora, S & Gupta, A \\
\hline 20 & Marzetta, TL & Cimino, JJ & Oja, E & Verdu, S \\
\hline 21 & Oja, E & Osher, S & Schapire, RE & Jordan, MI \\
\hline 22 & Bartlett, PL & Kikinis, R & Lapidoth, A & Lee, J \\
\hline 23 & Bro, R & Leinen, $\mathrm{P}$ & Bartlett, PL & Viergever, MA \\
\hline 24 & Schapire, RE & Ross, JM & Marzetta, TL & Yu, PS \\
\hline 25 & Forney, GD & Curtis, HW & Bro, $\mathrm{R}$ & Freund, RM \\
\hline 26 & Scholkopf, B & Montrose, CJ & Bey, J & Schapire, RE \\
\hline 27 & Murley, PC & Muhlfeld, HP & Forney, GD & Vardy, A \\
\hline 28 & Lapidoth, A & OGorman, TJ & Warmuth, MK & Leinen, $\mathrm{P}$ \\
\hline 29 & Leinen, $\mathrm{P}$ & Motwani, R & Zuckerman, D & Amari, S \\
\hline 30 & Amari, $\mathrm{S}$ & Schapire, RE & Scholkopf, B & Alon, $\mathrm{N}$ \\
\hline 31 & Overhage, JM & Tarokh, V & Sharir, M & Motwani, R \\
\hline 32 & Szegedy, M & Viergever, MA & Helleseth, T & Goldreich, $\mathrm{O}$ \\
\hline 33 & Shu, CW & Jordan, MI & Shortliffe, EH & Bartlett, PL \\
\hline 34 & Williamson, DP & Paxson, V & Duin, RPW & Szeliski, R \\
\hline 35 & Warmuth, MK & Kim, J & Amari, S & Kittler, J \\
\hline 36 & Duin, RPW & Amari, S & Hochwald, BM & Breiman, L \\
\hline 37 & Lin, YB & Vardy, A & Lin, YB & Feige, U \\
\hline 38 & Kimmel, R & Bey, J & Kimmel, R & Hochwald, BM \\
\hline 39 & Shahar, Y & Lakshman, TV & Jordan, MI & Bey, J \\
\hline 40 & Helleseth, T & Feige, U & Calderbank, AR & Sharir, M \\
\hline 41 & Jordan, MI & Yu, PS & Mesiar, R & Black, MJ \\
\hline 42 & Campbell, KE & Arora, S & Williamson, DP & Jain, $R$ \\
\hline 43 & Long, PM & Breiman, L & Shu, CW & Towsley, D \\
\hline 44 & Sharir, M & Willinger, W & Long, PM & Lakshman, TV \\
\hline 45 & Musen, MA & Vera, JR & Renegar, J & Kim, J \\
\hline 46 & Freund, Y & Tanaka, K & Freund, $\mathrm{Y}$ & Paxson, V \\
\hline 47 & Bey, J & Shor, PW & Shahar, Y & Richardson, TJ \\
\hline 48 & Hochwald, BM & Verdu, S & Szegedy, M & Tanaka, K \\
\hline 49 & Calderbank, AR & Jain, $R$ & Breiman, L & Kikinis, $\mathrm{R}$ \\
\hline 50 & Greenes, RA & Hill, DLG & Bates, DW & MacKay, DJC \\
\hline
\end{tabular}


Table A.3 Top 50 researchers by both kinds of rankings (part 3)

\begin{tabular}{|c|c|c|c|c|}
\hline & coauthors & coauthorsT & distCoauthors & distCoauthorsT \\
\hline 1 & Srinivasan, GR & Srinivasan, GR & Srinivasan, GR & Srinivasan, GR \\
\hline 2 & Ziegler, JF & Murley, PC & Ziegler, JF & Murley, PC \\
\hline 3 & Freeman, LB & Ziegler, JF & Freeman, LB & Ziegler, JF \\
\hline 4 & Murley, PC & Freeman, LB & Murley, PC & Freeman, LB \\
\hline 5 & Tang, HHK & Tang, HHK & Tang, HHK & Tang, HHK \\
\hline 6 & Leinen, $\mathrm{P}$ & Leinen, $\mathrm{P}$ & Leinen, $\mathrm{P}$ & Leinen, $\mathrm{P}$ \\
\hline 7 & Bey, J & Bey, J & Bey, J & Bey, J \\
\hline 8 & Juang, JG & Juang, JG & Juang, JG & Juang, JG \\
\hline 9 & Juang, HG & Juang, HG & Juang, HG & Juang, HG \\
\hline 10 & Wiener, N & Wiener, N & Wiener, N & Wiener, N \\
\hline 11 & Korec, I & Curtis, HW & Korec, I & Curtis, HW \\
\hline 12 & Cegielski, $\mathrm{P}$ & Montrose, CJ & Cegielski, P & Montrose, CJ \\
\hline 13 & Curtis, HW & Muhlfeld, HP & Curtis, HW & Muhlfeld, HP \\
\hline 14 & Montrose, CJ & OGorman, TJ & Montrose, CJ & OGorman, TJ \\
\hline 15 & Muhlfeld, HP & Ross, JM & Muhlfeld, HP & Ross, JM \\
\hline 16 & OGorman, TJ & Korec, I & OGorman, TJ & Korec, I \\
\hline 17 & Ross, JM & Cegielski, P & Ross, JM & Cegielski, $\mathrm{P}$ \\
\hline 18 & Renegar, J & Taber, $\mathrm{AH}$ & Renegar, J & Taber, $\mathrm{AH}$ \\
\hline 19 & Sudan, M & Walsh, JL & Muses, C & Walsh, JL \\
\hline 20 & Schapire, RE & Muses, C & Simon, DR & Muses, C \\
\hline 21 & Simon, DR & Renegar, J & Litkowski, KC & Renegar, J \\
\hline 22 & Muses, C & Litkowski, KC & McTavish, DG & Litkowski, KC \\
\hline 23 & Litkowski, KC & Simon, DR & Gazarik, MJ & McTavish, DG \\
\hline 24 & McTavish, DG & McTavish, DG & Kamen, EW & Simon, DR \\
\hline 25 & Vazirani, U & Gazarik, MJ & Prou, JM & Gazarik, MJ \\
\hline 26 & Bernstein, E & Kamen, EW & Wagneur, E & Kamen, EW \\
\hline 27 & Taber, AH & Prou, JM & Sudan, M & Prou, JM \\
\hline 28 & Walsh, JL & Wagneur, E & Taber, $\mathrm{AH}$ & Wagneur, E \\
\hline 29 & Ristow, GH & Fidelman, U & Walsh, JL & Fidelman, U \\
\hline 30 & Fidelman, U & Ristow, GH & Ristow, GH & Ristow, GH \\
\hline 31 & Gazarik, MJ & Vazirani, U & Fidelman, U & Vazirani, U \\
\hline 32 & Kamen, EW & Bernstein, $E$ & Vazirani, U & Bernstein, E \\
\hline 33 & Prou, JM & Robinson, DL & Bernstein, E & Robinson, DL \\
\hline 34 & Wagneur, E & Myers, JS & Schapire, RE & Myers, JS \\
\hline 35 & Bennett, $\mathrm{CH}$ & Sampson, G & Bennett, $\mathrm{CH}$ & Sampson, G \\
\hline 36 & Shamai, S & Thomason, $\mathrm{A}$ & Robinson, DL & Thomason, A \\
\hline 37 & Osher, S & Yngve, VH & Breiman, L & Yngve, VH \\
\hline 38 & Breiman, L & Sudan, M & Myers, JS & Sudan, M \\
\hline 39 & Jain, AK & Bennett, $\mathrm{CH}$ & Sampson, G & Wang, WY \\
\hline 40 & Tarokh, V & Wang, WY & Thomason, A & Schwarzer, S \\
\hline 41 & Myers, JS & Breiman, L & Yngve, VH & Wachmann, B \\
\hline 42 & Sampson, G & Schwarzer, S & Jain, AK & Russell, CA \\
\hline 43 & Thomason, A & Wachmann, B & Shamai, S & Chin, B \\
\hline 44 & Yngve, VH & Russell, CA & Schwarzer, S & Enger, TA \\
\hline 45 & Robinson, DL & Chin, B & Wachmann, B & Hosier, $\mathrm{P}$ \\
\hline 46 & Calderbank, AR & Enger, TA & Calderbank, AR & Klein, WA \\
\hline 47 & Sapiro, G & Hosier, $\mathrm{P}$ & Tarokh, V & LaFave, LE \\
\hline 48 & Freund, Y & Klein, WA & Freund, RM & Messina, B \\
\hline 49 & Schwarzer, S & LaFave, LE & McEliece, RJ & Nicewicz, M \\
\hline 50 & Wachmann, B & Messina, B & Behbehani, J & Orro, JM \\
\hline
\end{tabular}

